\title{
The Innate Immune System in Demyelinating Disease
}

\author{
Lior Mayo ${ }^{1}$, Francisco J. Quintana ${ }^{1}$, and Howard L. Weiner ${ }^{1}$ \\ ${ }^{1}$ Center for Neurologic Diseases, Brigham and Women's Hospital, Harvard Medical School, \\ Boston, MA, USA
}

\section{Summary}

Demyelinating diseases such as multiple sclerosis are chronic inflammatory autoimmune diseases with a heterogeneous clinical presentation and course. Both the adaptive and the innate immune systems have been suggested to contribute to their pathogenesis and recovery. In this review, we discuss the role of the innate immune system in mediating demyelinating diseases. In particular, we provide an overview of the anti-inflammatory or pro-inflammatory functions of dendritic cells, mast cells, natural killer (NK) cells, NK-T cells, $\gamma \delta$ T cells, microglial cells, and astrocytes. We emphasize the interaction of astroctyes with the immune system and how this interaction relates to the demyelinating pathologies. Given the pivotal role of the innate immune system, it is possible that targeting these cells may provide an effective therapeutic approach for demyelinating diseases.

\section{Keywords}

innate immunity; astrocyte; demyelination; multiple sclerosis; central nervous system

\section{Introduction}

Demyelination is the pathological removal of myelin sheaths that surround axons and enhance axonal function. Spontaneous remyelination by oligodendrocytes that mature from oligodendrocyte precursor cells may occur following demyelination, presumably allowing a partial, if not complete, recovery from disability. The balance between demyelination and remyelination during demyelinating pathologies is mediated by the immune system (both the adaptive and the innate) and determines the outcome of the disease (1-3).

The major disease in this category is multiple sclerosis (MS). MS is a chronic inflammatory demyelinating autoimmune disease of the central nervous system (CNS) of unknown etiology and heterogeneous clinical symptoms and course (4). Depending upon clinical presentation and course, MS is classified either as relapsing remitting (RR), primary progressive (PP), or secondary progressive (SP). Approximately 85\% of MS patients initially exhibit a RR course, characterized by acute attacks (relapse) followed by partial or full recovery (remission), which occurs at variable intervals. Of these RR-MS patients, about two-thirds of the untreated patients transition to the secondary progressive phase at which time neurologic disability accumulates in the absence of attacks (3). About $15 \%$ of MS patients have a primary progressive course manifested by progressive clinical worsening from onset with no clinical attacks (5). Other, more rare forms of demyelinating diseases include (i) neuromyelitis optica (NMO), in which there is an adaptive immune response

Address for Correspondence: Howard L. Weiner, 77 Avenue Louis Pasteur, HIM Bldg 720, Boston, MA 02115, USA, Tel.: +1 617 525 5300, Fax: +1 617525 5252, hweiner@ rics.bwh.harvard.edu.

The authors declare no conflicts of interest. 
directed against the water channel aquaporin 4 (AQP4), (ii) acute disseminated encephalomyelitis (ADEM), which is characterized by a monophasic immune mediated attack against the CNS and which has been suggested to be a variant of MS (6), and (iii) paraneoplastic syndromes in which the adaptive immune response targets cancer antigens shared by epitopes in the nervous system, including myelin (7).

Animal models of demyelinating diseases are central for our understanding of the molecular and cellular mechanisms underlying the pathogenesis of these diseases. Moreover, most of the therapies used in MS, emerged from experiments in these models (reviewed in 8, 9). The three most commonly studied categories of demyelinating animal models are: (i) toxininduced models of demyelination, including the cuprizone model and focal demyelination induced by lysophosphatidyl choline (lysolecithine); (ii) virally induced chronic demyelinating disease models, the primary example of which is Theiler's murine encephalomyelitis virus (TMEV) infection, and (iii) purely autoimmune driven models, which are the most commonly used, including the classic autoimmune model experimental autoimmune/allergic encephalomyelitis (EAE) (Fig 1). In the cuprizone model, demyelination is induced by degeneration of oligodendrocytes rather than by a direct attack on the myelin sheath. This phenotype is mediated by the innate system (central and peripheral) with little or no participation of adaptive immunity and is reversed once the toxin is removed, thus allowing remyelination $(8,10,11)$. In the TMEV model, virus infection of the susceptible (SJL/J) mouse strain leads to the induction of myelin-specific T cells, resulting in a progressive disease course, similar to the primary progressive MS $(8,12)$. Finally, the EAE model is an inducible $\mathrm{CD} 4^{+} \mathrm{T}$-cell mediated model of MS that exhibits different strain-specific disease phenotypes, ranging from monophasic to relapsing to progressive disease $(3,8,13)$.

An important concept that has emerged in recent years is that the peripheral innate immune system plays a significant role during neuroinflammatory pathologies. In line with this, when patients transition from the relapsing-remitting to the progressive stage of MS, changes in the cytokines profile and costimulatory molecule expression are observed in their dendritic cells (DCs) (3, 14-16). Moreover, we have recently demonstrated that in mouse models of SPMS, central innate immune cells, such as astrocytes, promote disease progression and are potential targets for therapeutic intervention (13, 17). Taken together, there is a growing recognition of the importance of the innate immune system in regulating and mediating demyelinating pathology, particularly in the progressive phase of MS.

In this review, we discuss the role of the innate immune system in the pathogenesis of demyelinating diseases (Fig. 2). We focus on the unique features of CNS innate immunity and the role of the innate cells that participate in those pathologies, including DCs, mast cells, natural killer (NK) cells, NKT cells, $\gamma \delta \mathrm{T}$ cells, microglial cells, and with a special emphasis on the role of astrocytes.

\section{The innate immune system}

Innate immunity is the first line of defense against infections. It is phylogenetically the oldest mechanism of defense against microbes and is present in all multicellular organisms including plants and insects. Innate immunity serves two main functions. First, it provides the initial response against microbes to prevent, control, and eliminate infections. Second, with the evolution of the adaptive immunity (beginning with the jawed vertebrates), the innate immune system developed the ability to stimulate and modulate adaptive immunity.

Innate immunity is a multi-component system. The first line of defense includes cellular barriers, such as the skin, the mucosal surfaces and of the gastrointestinal and respiratory tracts, and more relevant to this review, the blood brain barrier (BBB), which has 
remarkable similarities to the peripheral barriers such as the gastrointestinal barrier. The second line of defense is composed of the innate immune cells, mostly of myeloid origin, including DCs, macrophages, monocytes, NK cells, NKT cells, mast cells, granulocytes, and $\gamma \delta \mathrm{T}$ cells in the periphery, and microglia cells in the CNS. Innate immunity also includes non-myeloid cells such as thymic epithelial cells in the periphery and astrocytes in the CNS.

\section{The role of the BBB}

The role of BBB is to restrict the accesses of chemical/biological compounds, pathogens, and immune cells into the brain. This phenomenon was first described by Paul Ehrlich in 1885 , when he noted that hydrophilic dyes injected directly to the blood stream exhibited little or no staining of the brain (but were highly visible in most organs). Over a century later, we now view the BBB as a complex barrier composed of endothelial cells, astrocytes, pericytes, and myeloid cells such as perivascular macrophages and mast cells (18-20).

In demyelinating disorders, the entry of cells from the periphery to the CNS (both regulators of the immune response or cells directly involved in the demyelinating process) is critical in disease pathologies. Hence, the regulation of the BBB integrity and the adhesion molecules and factors secreted from it play a pivotal role (21-24). Consistent with this notion, an effective treatment for the relapsing forms of MS is natalizumab, which acts by inhibiting the T cells' ability to enter the brain by blocking their interaction with adhesion molecules on the BBB's endothelial cells. In this review, we also address how the innate cells affect BBB integrity and function.

The cellular innate immune response to stimuli is at most limited to known patterns, which are pre-coded in the germline (see below, neuroimmunology); therefore, unlike adaptive immunity, it lacks the diversity and specification that arises from somatic rearrangements and has no immunological memory. This is accomplished through an array of pattern recognition receptors (PRRs) that reside in specific subcellular compartments and bind pathogen-associated molecular patterns (PAMPs). Among the PAMP family of receptors, there are Toll-like receptors (TLR), NOD-like receptors (NLRs), C-type lectin receptors (CLRs), and RIG-I-like receptors (RLRs) (25-29). PRRs also recognize self-molecules that are released after cell damage or death, known as danger-associated molecular patterns (DAMPs), which include a diverse repertoire of ligands such as genomic double-stranded DNA, proteins [e.g. heat-shock proteins (HSPs)], and purinergic metabolites. Those molecules may interact with the PRRs or unique receptors such as the P2x receptor family [recognizing extracellular adenosine triphosphate (ATP)], or CD38 [recognizing extracellular nicotinamide adenine dinucleotide (NAD)]. Our understanding of endogenous (self) activation of the PRRs is slowly changing as it becomes increasingly evident that the PAMPs receptor family, on top of their conventional response to pathogen antigens, also responds to endogenous host molecules that trigger inflammatory responses. Thus, they play an important role in autoimmunity. For example, dying cells in the brain may release extracellular purinergic metabolites such as ATP and NAD leading to innate (and adaptive) activation (30-33), and the uptake of double-stranded DNA can induce activation of TLRs. The HSP60, HSP70, and high-mobility group box 1 (HMGB1) proteins, suspected to have an important role in MS progression (34-38), can also activate different TLRs (39-42) and CLRs $(25,43,44)$, affecting cytokine production and antigen presentation. Hence, the activation of the PPRs seems to play an important role in the regulation of the demyelinating pathologies, either by activation by disease-associated pathogens, such as the Epstein-Barr virus in MS (45-47), or responding to endogenous stimuli $(35,37,38,48)$.

Innate effector functions are elaborate and may include (i) nitric oxide production and respiratory burst, which is aimed at generating oxidative DNA damage to nearby pathogenic organisms but which may also cause neuronal and oligodendrocyte cell death, as well as 
affecting the immune response, (ii) phagocytosis of pathogens, dying cells, and myelin, (iii) cytokine and chemokine production, (iv) antigen presentation to adaptive immune cells, (v) secretion of trophic factors, or (vi) release of soluble proteins such as matrix metalloproteinases (MMPs) affecting the extracellular matrix and the BBB.

\section{Neuroimmunology}

In considering innate immunity in the CNS, the concept of 'immune privilege' is very important. For many years, the CNS was considered to be immune privileged, as heterologous tissue transplanted into CNS was spared from immunological rejection, presumably because the CNS is isolated form the immune system by the BBB, lacks draining lymphatics, and its resident macrophages were considered less competent immunologically in comparison to their peripheral counterparts. CNS autoimmunity and neurodegeneration were consequently regarded as resulting from immune cell encounter with CNS antigens. This notion had to undergo a dramatic transformation with the discovery that peripheral immune cells enter the CNS [e.g. T-helper 17 (Th17) cells migrate to the uninflamed CNS via the choroid plexus (49)] and that neurodegeneration and demyelination occur in the absence of substantial infiltration of peripheral immune cells. Furthermore, certain aspects of inflammation may in fact be required for remyelination, and CNS-resident innate immune cells (mainly microglia and astrocytes) are not incompetent but actively maintain a tolerogenic CNS environment $(1,50-53)$.

As the concept of CNS immune privilege expands, investigations have begun to elucidate the extent to which CNS neurons, microglia, and astrocytes actively regulate immune responses. Neurons play an important part in maintaining a quiescent immunological profile of microglial cells by constant expression of ligands such as CD22, CD200, and CX3CL1 (fractalkine)(50,52). Remarkably, the downregulation of those molecules, as a result of neural stress, triggers microglial activation (even in the absence of PPRs signaling). For example, in mice lacking CD200, normally expressed on neurons, the microglia show an activated phenotype with changes in morphology and expression of major histocompatibility complex (MHC) class II, which is associate with more severe disease in the EAE model (54, 55). It is unclear whether similar mechanisms of immune regulation are associated with astrocytes. Other mechanisms that may contribute to innate immune regulation in the CNS are the absence of serum proteins (known to activate phagocytes), the presence of antiinflammatory cytokines such as transforming growth factor- $\beta$ (TGF $\beta$ ) and prostaglandin E2 (PGE2) (52), and the expression of specific microRNAs. For example, we have recently shown that microRNA-124 is expressed in microglia cells but not peripheral monocytes promoting microglia quiescence in the healthy CNS (56). Interestingly, microRNA-124 is down regulated in EAE, and artificial downregulation of microRNA-124 induces microglial activation in vitro and aggravates $\mathrm{EAE}$ in vivo (56).

A further dimension of CNS immunity is that known immunological molecules, such as proinflammatory cytokines [e.g. tumor necrosis factor-a (TNFa) and interleukin-6 (IL-6)], components of the histocompatibility protein complex, and elements of the complement cascade, not only have classic immunological functions but have a dual role in influencing the development of the nervous system (57).

\section{Dendritic cells}

DCs are professional antigen-presenting cells (APCs) that play an important role in promoting the activation and differentiation of naive $\mathrm{T}$ cells as well as memory $\mathrm{T}$ cells. DCs are a diverse cell type made up of several subsets based on the expression of their surface markers. Two main subsets are recognized: myeloid DCs $\left(\mathrm{CD} 11 \mathrm{c}^{+}\right.$, also called conventional 
DCs) and plasmacytoid DCs (CD11 $\left.\mathrm{c}^{\mathrm{dim}}\right)$. DCs can be further subdivided into different subsets based on other markers, such as CD8 or the newly identified CD141 $(58,59)$.

The interaction of DCs with $\mathrm{CD} 4{ }^{+} \mathrm{T}$ cells is crucial in determining T-cell differentiation into either effector T cells (Th1, Th2, Th9, and Th17 cells) or regulatory T cells [forkhead box protein 3 (Foxp3) ${ }^{+}$Tregs and Tr1 cells], thus shaping the adaptive response (60-62). DCs are also important for the activation of $\mathrm{CD}^{+} \mathrm{T}$ cells and can induce either cytotoxic or regulatory NK cells (reviewed in 63).

In animal EAE models, $\mathrm{CD} 11 \mathrm{c}^{+} \mathrm{DCs}$ were found to be the only APC required for the initiation of adoptive transfer EAE using a transgenic mouse in which $\mathrm{H} 2-\mathrm{Ab} 1$ (MHC class II) expression was targeted specifically to the DCs of $\mathrm{H} 2-\mathrm{Ab}^{-/-}$mice (i.e. MHC class II is exclusively restricted to $\left.\mathrm{CD} 11 \mathrm{c}^{+} \mathrm{DCs}\right)$, and augmenting the numbers of DCs directly correlated with disease severity (64). DCs were also shown to be the most effective APC in the CNS in mediating epitope spreading in different EAE models $(65,66)$. Moreover, manipulating DC function alters the T-cell repertoire, thus affecting the disease course. We have demonstrated that increased osteopontin (OPN) expression in DCs amplifies the Th17 T-cell compartment and that DCs modified by interferon- $\gamma$ (IFN $\gamma$ ) acquire IL-27-dependent regulatory function, promote IL-10-mediated T-cell tolerance, thus either augmenting (OPN) or suppressing the autoimmune inflammation and clinical severity of EAE $(67,68)$. Conversely, we have also found that aryl hydrocarbon receptor (AhR) signaling is antiinflammatory (69), and targeting DCs with nanoparticles containing AHR ligands and myelin peptides may be used to induce antigen specific tolerance (authors' unpublished results).

In MS patients, DCs are found in MS lesions $(64,65,70)$, and DCs isolated from the peripheral blood of MS patients exhibit an altered phenotype with decreased or delayed expression of the activation markers CD86, CD83, and CD40 in addition to their altered functionality in terms of T-cell proliferation and generation of regulatory $\mathrm{T}$ cells (71). Moreover, we found changes in the cytokine profile and expression of costimulatory and inhibitory molecules in SPMS versus RRMS $(3,14-16)$. Taken together, these studies suggest that DCs are important in promoting disease progression in MS and EAE and are also linked to transition from the RR to the SP phase of MS.

\section{NK cells}

NK cells contribute to both effector and regulatory functions of innate immunity via their cytotoxic activity and their ability to secrete pro- and anti- inflammatory cytokines and growth factors. NK cells respond to low or absent expression of MHC class I molecules on cells (frequently observed in tumors or in virus infected cells), yet it had been postulated that in an autoimmune context, the inflammatory milieu is sufficient to trigger NK activation (72). To date, several human NK subsets were defined based on surface marker expression including (i) $\mathrm{CD} 56^{\mathrm{dim}} \mathrm{CD} 16^{+} \mathrm{NK}$ cells, a cytolytic subset, (ii) $\mathrm{CD} 56^{\text {bright }} \mathrm{CD} 16^{-}$cells that lacks perforin, or (iii) $\mathrm{CD} 8^{\text {low }} \mathrm{CD}^{+} 6^{+}$that were reported to be reduced in RRMS patients. Alternately, they can be defined by their cytokine profile, namely NK1 and NK2, expressing IFN $\gamma(\mathrm{NK} 1)$ or IL5 and IL13 (NK2) $(72,73)$.

The role of NK cells in demyelinating pathologies, in agreement with the polarity of their known subtypes, suggest that they can either enhance or ameliorate disease, as observed by in vitro studies, animal models, and in MS. In vitro data demonstrate an array of toxicities of NK cells towards immune and CNS resident cells, including the direct lysis of primary oligodendrocytes and neurons, and to some extent microglia, astrocytes, DCs, and T cells (the latter, by CD95L expression) (72, 74-76). 
EAE studies demonstrated that EAE induced in NK-depleted rats resulted in more severe disease and that IL-18, and IL-21 enhancement of EAE was NK dependent, thus suggesting the NK cells are important for disease progression (77-79). Yet, a larger body of work, utilizing antibody- mediated $\mathrm{NK}$ depletion, transgenic mice $\left(\mathrm{Cx} 3 \mathrm{CR} 1^{\mathrm{GFP}+/ \mathrm{GFP}+}\right)$ in which NK cell homing to the CNS was interrupted, and EAE induced in mice in which NK cells were enriched in vivo (following IL-2 complex treatment), demonstrated that NK cells have a protective role in EAE. This phenotype demonstrated reduced clinical severity and demyelination, coupled with a reduction in Th17 cells, changes to the microglia and DCs phenotypes, and even the production of neurotrophic factors by the NK cells (80).

Studies in humans also support a protective role for NK cells in MS. CD95 ${ }^{+}$(Fas) NK cells expand during remission (74) and are postulated to kill activated T cells. In MS clinical trials with a humanized antibody against the IL-2 receptor a chain (daclizumab), only marginal effects on $\mathrm{CD} 4^{+} \mathrm{T}$ cells were reported, while an expansion of CD56 bright immunoregulatory NK cells was consistently observed (similar to the NK expansion in EAE reported above), which in turn was highly correlated with the reduction of the inflammatory activity (81). Interestingly, both the frequencies of CD56 ${ }^{\text {bright }}$ immunoregulatory NK cells and the $\mathrm{CD} 8{ }^{\text {low }} \mathrm{CD}^{2} 6^{+} \mathrm{NK}$ cells are reduced in MS $(73,82)$, yet NK2 immunoregulatory cells were reported to recover to normal levels during remissions (83). Taken together, these data show that NK cells may play a regulatory role in modulating demyelination by affecting the activation and the survival of autoreactive $\mathrm{T}$ cells and other innate cells through cytokine production and direct cytotoxicity.

\section{Mast cells}

Mast cells are regarded as the first line of defense of the innate immune system, and although mast cells are found in peripheral tissues such as the skin, gut, and the respiratory tract, they can also be found in the CNS (particularly in perivascular locations as part of the BBB). Mast cells are known for their role in allergic reactions, where they are activated by cross-linking of the high affinity IgE receptor (FceRI), but they also have an important role in autoimmune disease such as MS, rheumatoid arthritis, and type 1 diabetes. Mast cells are classically activated by IgG-antigen complexes, but are also induced by other factors including PAMPs, complement, cell-cell contact and cytokines. These stimuli can result in the release of both preformed and newly synthesized mediators. The release of preformed molecules is regulated by the secretion of different granules containing histamine, serotonin, tryptase, chymase, as well as the lipid-derived mediators prostaglandin D2 (PGD2) and leukotriene B4 (LTB4), while newly synthesized mediators include cytokines, chemokines and MMPs (19, 39, 52, 84-88).

Mast cells are observed at sites of inflammatory demyelination in the brain and spinal cord of MS patients as well as in rodents with $\operatorname{EAE~}(89,90)$. Elevated levels of tryptase, a mast cell-specific protease, was detected in the cerebrospinal fluid of MS patients, as well as changes in blood histamine levels $(45,47,91-93)$. Notably, peripheral histamine may increase BBB permeability $(19,89)$. Microarray analysis of MS lesions shows that transcripts encoding tryptase, histamine R1, and FceRI are increased in chronic disease (9496). In vitro, myelin can directly stimulate mast cell degranulation, and mast cell proteases can degrade myelin proteins as well as activate pro-MMP-2 and Pro-MMP-9 and degrade the MMP inhibitor TIMP-1 (thus potentially supporting BBB breakdown) $(21,23,24,97$, 98).

The most direct evidence for the role of mast cells in demyelination comes from studies utilizing mast cell-deficient mice in EAE models with different disease courses (Fig. 1) $\left(\mathrm{MOG}_{35-55}\right.$ induced in $\mathrm{C} 57 \mathrm{Bl} / 6$ mice or PLP $139-151$ induced in SJL mice), in which mast 
cell-deficient mice exhibited significantly reduced disease severity $(25,27,99)$. Similar results were obtained when key functions of mast cells were inhibited during EAE, by treating the mice with a degranulation inhibitor (proxicromil), a serotonin receptor antagonist (cyproheptadine), or a depletor of vasoactive amines in mast cell granules (reserpine) $(30,32,100)$.

Mast cells have been shown to interact with different cells of the innate and adaptive immune systems. Mast cells can reduce Treg suppressive function by expressing OX40L or by secretion of histamine and can promote the differentiation of Th17 cells $(34,36,97)$. Mast cells can also affect B-cell survival, proliferation, and differentiation into CD138 ${ }^{+}$ plasma cells $(39,101)$, yet it is still unclear what role the mast cells play in adaptive interactions in demyelination. In the CNS, mast cells are closely associated with astrocytes and the BBB, and indeed, when EAE was induced in mast cell-deficient mice, there was a reduced permeability of the BBB and cell infiltration $(25,99)$. Mast cells appear to play a role in rendering the CNS more susceptible to infiltration of immune cells, thus promoting inflammation and demyelination.

\section{Invariant NKT cells}

NKT cells are a subset of $\mathrm{T}$ cells shown to have a crucial role in promoting immunity to tumors, bacteria, and viruses, and in suppressing cell-mediated autoimmunity. NKT cells have a T-cell receptor of limited diversity that recognizes lipid antigen presented by the nonclassical MHC class I molecule CD1d. The term NKT was originally given to this cell based on their expression of antigens associated with the NK lineage, but this classification of NKT cells is problematic, as it does not define a T-cell lineage with unique phenotypical or functional attributes. Mouse and human NKT cells harbor two distinct functionally subsets, $\mathrm{CD}^{+}{ }^{+} \mathrm{CD} 8^{-}$and $\mathrm{CD} 4^{-} \mathrm{CD}^{-}$, the first associated with $\mathrm{Th} 0$ type responses and the latter regarded as having a Th1 like phenotype. In humans a third subset, $\mathrm{CD} 4^{-} \mathrm{CD} 8^{+}$, was also identified. Activated NKT cells are considered as potent cytokine producers [including TNF, IFN $\gamma$, IL-10, IL-13, and granulocyte macrophage colony-stimulating factor (GM-CSF)] and may also have cytotoxic activity, though the latter is not considered part of one of their main effector functions (reviewed in 102).

Many lipids are released into the inflammatory milieu during demyelinating pathologies and can be presented by CD1d by DCs and macrophages $(103,104)$. NKT cells are known to alter the strength and character of immune responses through crosstalk with DCs, neutrophils, lymphocytes, and mononuclear phagocytes, thus NKT cells were suggested to have a clear role in diseases like MS (102). For example, IL-10-producing NKT cells were shown to be essential for induction of regulatory T cells (105), and NKT stimulation with agalactosylceramide (a-GalCer) elicited a Th2-like cytokine response (106).

In multiple mice stains, including C57BL/6, SJ/L, NOD, and NOD NKT-TCR-restricted transgenic mice, NKT cells have a regulatory effect on EAE progression, also in a CD1dindependent manner (104, 106-108). In MS patients NKT cells are reduced, have an abnormal cytokine production, and have altered responses to a-GalCer stimulation, a phenotype which is partially reversed following IFN $\beta$-treatment (109-112). These data support an association between MS and NKT cell defects and the notion of a regulatory role for NKT cells during demyelination.

\section{yo T cells}

$\gamma \delta$ T cells are a unique subset of lymphocytes that can be regarded as belonging to both the innate and adaptive immune systems. They have a limited $\gamma \delta$ TCR repertoire and recognize non-MHC restricted antigens as well as TLR ligands and cytokines (as costimulators) (45, 
$47,47,113)$. The exact nature of $\gamma \delta$ TCR ligands is not entirely clear, yet they seem to include non-protein microbial pathogens, endogenous heat shock proteins, and MHC I-like or MHC-I polypeptides related sequences such as Rae1. $\gamma \delta \mathrm{T}$ cells are present in abundance in skin and mucosal tissues, particularly intestinal epithelium, where they constitute up to $50 \%$ of the $\mathrm{T}$ cells, with only a minute presence $(1-5 \%)$ in peripheral blood $(48,52,53) . \gamma \delta$ $\mathrm{T}$ cells have demonstrated cytotoxic potential, either directly [e.g. FAS-FASL interaction (85) or indirectly by activating cytotoxic $\mathrm{CD} 8^{+}$cells (89)]. They can secrete cytokines (IL17) and chemokines $(45,47,91)$ and are suggested to efficiently process and display antigens and provide costimulatory signals sufficient for strong induction of naive a $\beta$ T-cell proliferation and differentiation (89).

The role of $\gamma \delta \mathrm{T}$ cells in demyelinating pathologies is not clear. In MS patients, several groups have reported the presence $\gamma \delta \mathrm{T}$ cells in MS plaques (with an enrichment to a TCRrestricted repertoire) $(94,96)$ and an increase in $\gamma \delta$ T cells in the $\operatorname{CSF}(97,98)$, which correlates with their increased number in peripheral blood (99) and high MRI activity(100). $\gamma \delta \mathrm{T}$ cells isolated from the CNS can be expanded but only from patients with recent-onset disease and not chronic MS patients (97), while expansion of CD16 $6^{+}$cytotoxic $\gamma \delta \mathrm{T}$ cells in MS patients was primarily observed during the progressive phase of disease (101), thus suggesting that these cells may have differential roles during various phases of the disease. Furthermore, $\gamma \delta \mathrm{T}$ cells isolated from the CNS of MS patients but not from patients with other neurological diseases respond to HSPs (HSP65 and HSP70), produce IL-2, proliferate, and demonstrate specific cytotoxic capabilities, such as lysis of oligodendrocytes (99). Although the antigen specificity and regulation of these cells is not well understood, it is clear that $\gamma \delta$ T cells are involved in the autoimmune inflammation in the CNS in MS.

To better understand the role of the $\gamma \delta$ T cells in MS and demyelination, groups have tried to induce EAE in $\gamma \delta$ T-cell 'deficient' mice (either by depleting the cells with an anti- $\gamma \delta$ TCR antibody or by using transgenic mouse models). However the role of $\gamma \delta$ T cells in EAE remains controversial, and opposing results were obtained using different strains and depletion methods, ranging from aggravating the clinical progression of EAE, having no effect on disease course, to showing a protective effect $(47,113)$. In conclusion, $\gamma \delta \mathrm{T}$ cells are increases in MS patients with 'active' or progressive disease and might contribute to disease pathology by exerting direct cytotoxic effects on oligodendrocytes, though additional studies are required to better understand their role in demyelination.

\section{Microglia, macrophages, and monocytes}

Microglial cells are the resident macrophage population of the CNS, which regulates local innate and adaptive immune responses in the CNS tissue. Microglial cells constitute up to $20 \%$ of the total glial population in the CNS and are distributed throughout the brain, spinal cord, and optical tissues and are estimated to be roughly equivalent in number to neurons (reviewed in 52, 53). In the healthy CNS, microglial cells are constantly actively surveying their surroundings $(114,115)$ ('resting' microglia) and acquire a reactive profile to cope with altered homeostasis (be it the result of infection, trauma, ischemia, neurodegenerative diseases, or altered neuronal activity). Microglial activation is rapid and profound and consists of a broad arsenal that includes the release of potentially cytotoxic molecules such as pro-inflammatory cytokines, reactive oxygen intermediates, proteinases (e.g. MMPs), and complement proteins. In addition, microglial cells recruit a variety of leukocytes (by chemokines secretion) as well as performing phagocytosis of debris, apoptotic cells and pathogens, and consequent antigen presentation to T cells. On the other hand, microglia cells also play a nourishing and anti-inflammatory role by secreting growth factors and antiinflammatory cytokines $(52,53)$. In line with the phenotypic diversity of active microglia, it appears that microglia in the healthy CNS do not constitute a single, uniform cell population 
but exhibit heterogeneous phenotypes in different regions of the CNS (53). For example, it was recently reported that white and gray matter microglia differ in the expression of the immunoregulatory receptor Tim-3, which affects their interaction with adaptive cells (116). In line with the notion that microglia are considered a self-sustaining population, at least in the adult organism, once the inflammatory response has faded, microglial cells return to their resting (surveying) state through a poorly understood de-activation process and excess cells undergo apoptosis while monocytes vanish from the CNS; thus the number of microglia cells return to normal to maintain homeostasis $(52,84,86,88)$.

CNS-invading inflammatory monocytes/macrophages cells from the periphery share several features with resident microglia, and both populations intermingle in CNS lesions, sharing both morphological and biochemical properties. The expression level of CD45 has been used to discriminate between resident microglia and infiltrating monocytes. Thus, microglial cells were considered as $\mathrm{CD} 11 \mathrm{~b}^{+} \mathrm{CD} 45^{\text {low/dim }}$, and infiltrating cells were considered $\mathrm{CD} 11 \mathrm{~b}^{+} \mathrm{CD} 45^{\text {high }}$. However, those definitions may not hold during chronic inflammation, and they lack sufficient specify $(53,117,118)$. Novel markers have recently been suggested to distinguish between microglial cells and inflammatory migrating monocytes. The monocytes are suggested to be characterized as $\mathrm{CD} 11 \mathrm{~b}^{+} \mathrm{Cx} 3 \mathrm{CR} 1^{+} \mathrm{Ly}_{6 \mathrm{C}}{ }^{\text {high }}$ and CCR2 ${ }^{+}$ cells (observed during acute stimulation); there is weak or no expression of these markers on microglial cells $(53,117,118)$. Nonetheless, these markers may also react with other immune cells under certain conditions [e.g. NK cells (119-121)]. Other markers for microglia have been suggested, such as the glucose transporter 5 (GLUT5) and P2Y12, yet none of those molecules has been well established $(53,122,123)$.

Microglia and inflammatory infiltrating monocytes (collectively referred to as mononuclear phagocytes) play a diverse role in demyelinating pathologies. In MS, activated phagocytes can be found in white matter lesions (early and late) and in gray matter subpial lesions (thought to be a critical determinant of disability in patients) $(3,124-127)$; similar observations were reported for NMO $(128,129)$.

In EAE studies, a marked reduction in disease severity was observed when activated microglia/monocytes were killed either by ganciclovir [GCV, a substrate of herpes simplex virus thymidine kinase (HSV-TK)] administration to EAE induced in CD11b-HSV-TK mice (130), or using clodronate liposomes (131).

In MS and EAE, microglia/monocyte cells were shown to be involved in demyelination and phagocytosis of the degraded myelin and neuronal debris $(132,133)$. They also have a role in antigen presentation to T cells, and play an important role in epitope spreading observed in Theiler's virus infection and EAE progression in SJ/L mice (though they are not as efficient as DCs) $(66,134)$. In vitro data also suggest that microglial cells can have toxic effects on oligodendrocytes. Inflammatory monocytes (identified as CCR $2^{+}$and/or Ly- $6 \mathrm{C}^{\text {high }}$ ) have been shown to promote EAE progression, in line with previous work from our laboratory demonstrating that the CCR2-deficient mice are resistant to EAE $(1,88,135-$ 138).

Microglia and macrophages can also support remyelination, promote neural survival, and suppress the adaptive immune response in the CNS $(1,53)$. Microglia and macrophages have been shown to have a beneficial role in toxin-induced demyelinating animal models (cuprizone and lysophosphatidylcholine), as remyelination was impaired after depletion of macrophages with clodronate liposomes $(139,140)$. Yet the relevance of these findings to human demyelinating diseases is still unclear. Microglia can also secrete growth factors such as NGF and BDNF, thus supporting neural survival; consistent with this, BDNF were found to be expressed by microglia/macrophages in MS lesions $(52,141)$. Microglia/macrophages 
can also decrease the adaptive immune response in the CNS by secreting IL-10, TGF $\beta$, and nitric oxide or by expressing inhibitory molecules such as PD-L1 (B7-h1) $(142,143)$ and inducing Tim-3 signaling (116).

In demyelinating pathologies, microglial and monocytes cells may perform both neurodestructive and neuro-protective functions. Switching their function from neuro-destructive to neuro-protective may be beneficial in preventing chronic demyelination and axonal loss and thus preventing disease progression (3).

\section{Astrocytes}

Astrocytes are the most abundant cell in the CNS. They account for nearly half of the brain's cells in humans and approximately one-third in mice. Historically, astrocytes were viewed as a relatively homogeneous cell population, defined as glial fibrillary acidic proteinexpressing $\left(\mathrm{GFAP}^{+}\right)$cells with either a fibroblast-like morphology (type I, mainly found in the white matter) or protoplasmic-shape (type II, found mainly in the gray matter), which play a role in the support and even regulation of neural tissue. Recent advances in astrocyte biology suggest, however, that those notions are outdated and that astrocytes are a diverse population of cells with functions related to both brain homeostasis and immunity (144).

Astrocytes are derived from the ectoderm during development. However, some astrocytes can be also be differentiated in the adult brain from NG2 glia cells, at least in the context of EAE, identifying them as a non-classic innate cells (of myeloid linage). Astrocyte diversity makes it harder to properly define these cells, and traditional markers such as $\mathrm{GFAP}^{+}$have been proven to be neither inclusive nor exclusive (other CNS-resident cells such as NG2 and pericytes cells have also been shown to be $\mathrm{GFAP}^{+}$); more recent markers such as GLAST and S100B face similar challenges (144-146). Due to extensive transcriptional studies, a novel pan-astrocyte marker was indentified, aldehyde dehydrogenase 1 family, member L1 (Aldh1L1)(147). Taken together, the different expression patterns of the astrocytic markers exemplify the diversity of the astrocytes and may suggest the existence of different astrocytes sub-types. However, before discussing the role of astrocytes in CNS immunity, two cautionary notes should be made: (i) much of our understating of astrocytes in innate immunity is based on in vivo studies using outdated definitions of astrocytes $(147,148)$, and (ii) in vitro data is largely based on primary culture systems that are usually contaminated with other CNS cells such as NG2, oligodendrocytes, epithelial cells, and more importantly microglia cells (up to $10 \%$, and even higher by standard protocols) $(148,149)$. Thus, although those issues are now being addressed by our laboratory and others (such as the use of a mixture of negative and positive selection to achieve higher culture purity) $(147,148)$, previous reports must be interpreted with caution and may even account for some of the discrepancies found in the literature regarding immune functions of the astrocytes.

Astrocyte activation has been associated with human demyelinating disorders such as MS (150), NMO (151, 152), and experimental models [including EAE $(13,17,153,154)$, TMEV $(12,155)$, and cuprizone-induced demyelination (156)]. One of the clearest demonstration of the importance of astrocytes in neuroinflammation comes from experiments with mice expressing the HSV-TK gene under the GFAP promoter, in which administration of GVC induces cell death in activated astrocytes. GFAP HSV-TK transgenic mice that were subjected to brain (157) or spinal cord (158) trauma or EAE induction (130, 159,160 ), demonstrated a more severe clinical phenotype, a breakdown of the BBB, elevated numbers of infiltrating immune cells (T-cells and monocytes), altered chemokine profiles (160), and increased demyelination $(150,161)$. We have found that in a progressive mouse model of MS, astrocytes play an important role via the TLR2/PARP1 pathway, and 
in fullerene-based anti-oxidant therapy (ABS-75), they markedly diminished disease progression $(13,17)$.

Astrocytes, as part of the innate immune system, express a large array of PPRs including TLRs, NLRs, and complement receptors $(150,161)$. Interestingly, only TLR3 is constitutively expressed by both mouse and human astrocytes, presumably making them more sensitive to viral infection (150). Astrocytes play an important role in demyelination (Table 1). Astrocytes secrete chemokines that attract both peripheral immune cells to the inflamed CNS (e.g. T cells, monocytes, and DCs), as well as resident CNS cells (microglia, NG2) to the lesions sites. For example, the chemokine CCL-2 (MCP-1) is upregulated by astrocytes in MS lesions and EAE, playing a fundamental role in the recruitment of inflamed monocytes to the CNS [consistent with this, we have shown that mice lacking the receptor for CCL2 are resistant to EAE (138)]. Chemokines produced by the astrocytes not only mobilize cells but also have the ability to shape neuroinflammation. For example, CXCL12 (SDF-1) is induced by MBP in vitro and is expressed by astrocytes in MS lesions (162). CXCL12 induces the production of CCL2 and CXCL8 (molecules that have been implicated in B-cell migration into the CNS) in human endothelial cells (163), supports astrocyte proliferation and activation (NF- $\kappa$ B activation, and TNF and IL-1 induction) $(164,165)$, regulates the survival and migration of NG2 cells (166-168), and when cleaved by MMP2 (also expressed by astrocytes in MS lesions and EAE models), is converted to a neurotoxic peptide (169). Astrocytes have also been reported to secrete various cytokines, growth factors, and other soluble proteins that shape the immune response (see below).

A major function of innate cells is to act as antigen-presenting cells. Though astrocytes express MHC class II under pathological conditions (170) and are capable of presenting myelin associated antigens (171), their ability to express costimulatory molecules (e.g. CD40, CD80, and CD86), either in vitro or in vivo, is still unclear, thus challenging their ability to act as APCs (reviewed in 172). A key component in antigen presentation is the cell's ability to phagocytose and process antigen. It is not clear, however, the extent to which astrocytes can perform phagocytosis or process and present antigens. Astrocytes have been found to express many of the genes associated with phagocytosis (147), and hypertrophic astrocytes were identified in acute MS lesions as cells capable of internalization of myelin debris through clathrin-coated pits (173). Astrocytes have been shown in vitro to engulf apoptotic encephalitogenic $\mathrm{T}$ lymphocytes (though less efficiently than microglial cells) (174) and to take up myelin peptides and present them to T cells. These observations have not been repeated with full proteins such as MOG or OVA (171, 175). Furthermore, it is not clear whether astrocytes can act as APCs in vivo under physiological conditions.

In line with their role as innate immune cells, astrocytes play an important part in the innate immunity's first line of defense at the physical barrier of the CNS, the BBB. Astrocytes not only participate during the formation of the BBB (20) but also are an integral part of the BBB. They stop the entry of immune cells to the CNS directly or indirectly by affecting the endothelial cells, mast cells and extra cellular matrix (ECM) of the BBB. Astrocytes directly affect cell entry to the CNS, via the BBB, by regulating the expression of adhesion molecules $(176,177)$, in particular intercellular adhesion molecule-1 (ICAM-1) and vascular cell adhesion molecule-1 (VCAM-1) that bind to the lymphocyte function-associated antigen-1 (LFA1) and very late antigen-4 (VLA4) receptors. They can also block the passage of cells thorough the BBB by inducing apoptosis in the infiltrating cells. Astrocytes constitutively express high levels of FAS ligand (FAS-L, CD95L) on the their end-feet, and astrocyte CD95L-induced T-cell apoptosis has been described both in vitro and in vivo (e.g. EAE model) (178-180). Notably, astrocytes have also been shown to induce T-cell apoptosis in rat and murine encephalitogenic $\mathrm{T}$ cells by other means, such as secretion of 
nitric oxide (181), osteonectin, and astrocyte-derived immune suppressor factor (AdIF) (182). Astrocytes may also control the passage of cells thorough the BBB by attenuating the characteristics of other components of the BBB, including the endothelial cells, mast cells, and the ECM. IL- 6 , TNFa, IL1- $\beta$, and TGF- $\beta$ are released by astrocytes during inflammation, and these factors act on endothelial cells and tight junctions to regulate permeability of the BBB $(20,183)$. Mast cells and astrocytes have been shown to interact in vitro (see below); yet, it is unclear how that interaction affects the BBB.

Changes in the composition of the ECM have been suggested to affect the progression of neurologic diseases. Astrocytes may affect the ECM in the BBB by either secreting MMPs, such as MMP2 and MMP9, that have been found to be induced by astrocytes both in vitro and in MS lesions(184-186), thus increasing the BBB permeability, or by secreting the MMPs inhibitor TIMP-1 (that was found to be regulated in MS models, and to be at normal or reduced levels in the serum and CSF of MS patients), hence tightening the BBB. MMPs secreted from the astrocyte (and from other cells such as microglia) may play other roles in the inflamed CNS, such as supporting remyelination (MMP9 and MMP12 or TIMP-1)(187) or attenuating chemotaxis (e.g. CCL2 cleavage by MMPs can reduce its activity or turn the cleaved peptide into an antagonist).

Astrocytes also play a role in another highly important physical barrier in the brain, the 'glial scar'. The glial scar is a physical barrier found around demyelinated lesions in MS and $\mathrm{EAE}$, and it is primarily composed of interwoven astrocytic processes held together by tight junctions $(159,188-190)$. The glial scar is thought to inhibit remyelination [though some have challenged this notion (191)], as it acts as physical barrier preventing OPCs/NG2 cells from migrating into the lesion (192). Furthermore, astrocytes express factors that inhibit the maturation of the OPCs into oligodendrocytes, such as fibroblast growth factor-2 (FGF-2) $(188,193,194)$, and even prevent axonal growth (195) by different ways such as the expressing of Neurocan proteoglycan, that was shown to inhibit axon growth in vitro(196) and has been associated with MS lesions and animal models $(197,198)$.

\section{Astrocytes modulate the activity of adaptive and innate immune cells in the CNS}

\section{T cells}

Astrocytic cross talk with $\mathrm{T}$ cells is extensive and may affect both the number and the phenotype of the T cells in the CNS (Fig. 3). Astrocytes attract CD4 $4^{+} \mathrm{T}$ cells to the CNS (and demyelinating lesions) by secreting chemokines, and regulating their entry thorough the BBB. However, in vivo data are inconclusive regarding the role of astrocytes in T-cell recruitment during EAE, as no changes in T-cell infiltration to the CNS was detected when activated astrocytes were paralyzed (HSV-TK GFAP mice model) $(159,160)$. In Act-1deficient astrocytes, however, when EAE progression is also reduced, a reduced infiltration of both $\mathrm{CD}^{+}$and $\mathrm{CD} 8^{+} \mathrm{T}$ cells coupled with a reduction in chemokine production was detected (153). CD24 expression in astrocytes has also been shown to regulate EAE severity and to contribute to the presence of Th17 cells in the CNS during EAE (199). Astrocytes may present antigen to the $\mathrm{CD} 4^{+} \mathrm{T}$ cells and secrete cytokines such as TGF $\beta$, IL-1, IL-6, IL-10, IL-12, IL-15, IL-23, and IL-27 (200) that have the potential of committing T cells to an pro-inflammatory phenotype (Th1, Th17) or to a regulatory phenotype (Treg, Tr1). In vitro experiments show that astrocytes can promote the differentiation of T cells into fully functional regulatory T cells that are capable of ameliorating EAE (201). Furthermore, astrocytes were shown to have elevated galectin-9 (Gal-9) expression in MS patients compared to healthy controls (116). T-cell immunoglobulin-3 (Tim-3) has been identified as a marker of differentiated Th1 and CD8 $8^{+} \mathrm{T}$ cytotoxic type 1 cells. The interaction of Tim-3 
with its ligand, Gal-9, induces T-cell dysfunction or apoptosis, and in-vivo blockade of this interaction results in exacerbated autoimmunity and abrogation of tolerance in experimental models (202). Thus Gal-9 expression on astrocytes may act to inhibit T-cell-mediated demyelination. On the other hand, astrocytes may secrete factors that promote induction of Th1 cells $(171,203)$, and in the presence of supporting cells (lymph nodes cells) also induce Th17 cells (204). The role of astrocytes in $\mathrm{CD}^{+} \mathrm{T}$-cell lineage commitment in the CNS is still unknown. Furthermore, astrocyte-driven IL-15 production, which have been observed in MS lesions, was demonstrated to have an important role in the encephalitogenic activity of CD8 ${ }^{+} \mathrm{T}$ cells (205).

T-cell associated cytokines, such as IFN $\gamma$ (Th1), IL-17 (Th-17), IL-9 (Th-9), and IL-10 and TGF $\beta$ (regulatory T cells), have all been shown to modulate different aspects of astrocyte activation including chemokine and cytokine production, regulation of MHC class II and costimulatory molecule expression, and secretion of MMPs and other soluble factors (150, 206, 207).

\section{B cells}

B-cell-activating factor belonging to the TNF family (BAFF) expression is important for Bcell survival, expansion, and activation. BAFF is produced by astrocytes and up-regulated in MS lesions, and in EAE-affected mice (208-210), suggesting that astrocyte-dependent BAFF expression may drive B-cell-dependent autoimmunity.

B cells may affect the astrocyte physiology by in an antibody-driven fashion, the clearest example being NMO, in which B cells produce antibodies against AQP4, the main water channel protein in the CNS, expressed on astrocyte end-feet at the BBB. Binding of NMOIgG to AQP4 can trigger complement activation and affect astrocyte physiology resulting in increased BBB permeability, inflammatory cell infiltration, and impaired glutamate uptake by astrocytes, leading to neurotoxicity $(211,212)$.

\section{Microglia/macrophages}

Astrocytes can modulate microglia and macrophage function in demyelinating disorders by a number of signals. They may affect monocyte migration thorough the BBB and modulate chemotaxic signals that recruit monocytes and microglia cells to the lesion sites. For example, astrocytes are a major source of CCL2 (MCP1) and CXCL10 (IP10) in MS and EAE, which regulate the migration of monocytes (CCL2-CCR2) into the brain, and the microglia (CXCL10-CXCR3) towards the lesion sites. However, when reactive astrocytes are depleted in mice induced with EAE, there is an increase in the numbers of Iba $1^{+}$cells (microglia/macrophages) and $\mathrm{CD} 11 \mathrm{~b}^{+} \mathrm{CD} 45^{\text {high }}$ (mainly macrophages), but not in $\mathrm{CD} 11 \mathrm{~b}^{+} \mathrm{CD} 45^{\mathrm{dim}}$ cells (presumably microglia cells) in the CNS, suggesting a more prominent role for astrocytes in regulating the recruitment of peripheral monocytes (159, 160). In vitro data indicate that in co-cultures of microglia and astrocytes or using astrocyteconditioned medium, astrocytes may regulate microglial secretion of IL-12 (213), induce hemeoxygenase-1 (HO-1) expression in microglia cells, thus favoring a more antiinflammatory phenotype (214). By secreting GM-CSF, M-CSF, or TGF, the astrocytes may regulate MHC class II expression on microglial cells (172) and even regulate microglial phagocytosis (215).

\section{DCs}

Astrocytes produce DC-attracting chemokines in vitro and in MS lesions (216). Yet, when EAE was induced in the HSV-TK mice, and activated astrocytes were depleted, more $\mathrm{CD} 11 \mathrm{c}^{+} \mathrm{CD} 45^{\text {high }}$ cells (DCs) were detected in the CNS (160), suggesting that astrocytes can also regulate DC numbers is the CNS by other mechanisms. 
NK cells

Little is known about the interaction between astrocytes and NK cells. Astrocytes secrete CXCL10, which attracts $\mathrm{Cx} 3 \mathrm{Cr} 1^{+} \mathrm{NK}$ cells to the CNS (Cx3Cr1-'deficient' NK cells were found to be excluded from the CNS) (217). Activated human NK cells kill astrocytes in vitro, and murine NK cells exacerbate the loss of GFAP and AQP4 expression in an ex vivo model of neuromyelitis optica $(76,218)$.

\section{Mast cells}

Mast cells and astrocytes share a perivascular localization (219). Astrocytes support the viability of mast cells in vitro $(43,44,219)$ and express receptors for histamine, a major constituent of mast cell granules. In addition, astrocytes produce cytokines or chemokines (e.g. IL-33) that cause mast cell degranulation and also express CD40L which activates mast cells $(35,37-39,220,221)$.

\section{Yठ T cells}

Human astrocytes expand $\gamma \delta$ T cells in vitro as a result of their high expression of HSPs, in contrast to other glia cells, including microglia cells, suggesting a possible interaction between the two cells types $(19,39,87,222)$. Yet, their role in demyelination disorders is unclear.

Astrocytes are emerging as an important innate immune cell in demyelinating diseases. Astrocytes act as gatekeepers to the CNS (in the BBB) and as the 'town herald' recruiting immune cells to lesion sites in the CNS. They may act directly or indirectly by affecting other cells, to induce cell damage, demyelination, and to inhibit remyelination. Astrocytes, in contrast, may acquire the opposing phenotype promoting cell survival, reducing inflammation, reestablishing CNS seclusion, and supporting remyelination. In some cases, such as NMO, they may be the direct target of the immune assault. In acute EAE, it appears that astrocytes have a regulatory role, yet it still unknown what role they play in chronic pathologies and during the course of MS and whether in these situations astrocytes could be manipulated to serve a therapeutic function.

\section{Summary}

Cells of the innate immune system may act in either a beneficial or detrimental fashion both in human and experimental disorders. On one hand, they may control autoimmunity by skewing the T-cell phenotype to a regulatory one, secreting neurotrophic growth factors and supporting remyelination. On the other hand, the innate immune system may play an immuno-pathogenic role by promoting the differentiation of Th1 and Th17 cells, which drive acute inflammatory events and can directly induce demyelination, kill neurons, and oligodendrocytes and prevent remyelination. Furthermore, the progressive phase of MS appears to driven by the innate immune system, which may directly contribute to the neurodegenerative changes that occur in progressive MS. Until now, there are no therapies that specifically target innate immune cells in MS. As the role of innate immunity in MS becomes better defined, it may be possible to better treat MS by targeting the innate immune system.

\section{Acknowledgments}

This work was supported by grants from the national multiple sclerosis society (NMSS) and the National Institutes of Health (NIH). 


\section{References}

1. Doring A, Yong VW. The good, the bad and the ugly. Macrophages/microglia with a focus on myelin repair. Front Biosci. 2011; 3:846-856.

2. Hanafy KA, Sloane JA. Regulation of remyelination in multiple sclerosis. FEBS Lett. 2011; 585:3821-3828. [PubMed: 21443876]

3. Weiner HL. A shift from adaptive to innate immunity: a potential mechanism of disease progression in multiple sclerosis. J Neurol. 2008; 255 (Suppl):3-11. [PubMed: 18317671]

4. Weiner HL. Multiple sclerosis is an inflammatory T-cell-mediated autoimmune disease. Arch Neurol. 2004; 61:1613-1615. [PubMed: 15477521]

5. Weiner HL. The challenge of multiple sclerosis: how do we cure a chronic heterogeneous disease? Ann Neurol. 2009; 65:239-248. [PubMed: 19334069]

6. Wender M. Acute disseminated encephalomyelitis (ADEM). J Neuroimmunol. 2011; 231:92-99. [PubMed: 21237518]

7. Darnell RB, Posner JB. Paraneoplastic syndromes affecting the nervous system. Semin Oncol. 2006; 33:270-298. [PubMed: 16769417]

8. Denic A, Johnson AJ, Bieber AJ, Warrington AE, Rodriguez M, Pirko I. The relevance of animal models in multiple sclerosis research. Pathophysiology. 2011; 18:21-29. [PubMed: 20537877]

9. Lopez-Diego RS, Weiner HL. Novel therapeutic strategies for multiple sclerosis--a multifaceted adversary. Nat Rev Drug Discov. 2008; 7:909-925. [PubMed: 18974749]

10. Kipp M, Clarner T, Dang J, Copray S, Beyer C. The cuprizone animal model: new insights into an old story. Acta Neuropathol. 2009; 118:723-736. [PubMed: 19763593]

11. Skripuletz T, Gudi V, Hackstette D, Stangel M. De- and remyelination in the CNS white and grey matter induced by cuprizone: the old, the new, and the unexpected. Histol Histopathol. 2011; 26:1585-1597. [PubMed: 21972097]

12. Kim BS, Palma JP, Kwon D, Fuller AC. Innate immune response induced by Theiler's murine encephalomyelitis virus infection. Immunol Res. 2005; 31:1-12. [PubMed: 15591618]

13. Basso AS, et al. Reversal of axonal loss and disability in a mouse model of progressive multiple sclerosis. J Clin Invest. 2008; 118:1532-1543. [PubMed: 18340379]

14. Karni A, Koldzic DN, Bharanidharan P, Khoury SJ, Weiner HL. IL-18 is linked to raised IFNgamma in multiple sclerosis and is induced by activated CD4(+) T cells via CD40-CD40 ligand interactions. J Neuroimmunol. 2002; 125:134-140. [PubMed: 11960649]

15. Karni A, et al. Innate immunity in multiple sclerosis: myeloid dendritic cells in secondary progressive multiple sclerosis are activated and drive a proinflammatory immune response. $\mathbf{J}$ Immunol. 2006; 177:4196-4202. [PubMed: 16951385]

16. Balashov KE, Smith DR, Khoury SJ, Hafler DA, Weiner HL. Increased interleukin 12 production in progressive multiple sclerosis: induction by activated CD4+ T cells via CD40 ligand. Proc Natl Acad Sci USA. 1997; 94:599-603. [PubMed: 9012830]

17. Farez MF, Quintana FJ, Gandhi R, Izquierdo G, Lucas M, Weiner HL. Toll-like receptor 2 and poly(ADP-ribose) polymerase 1 promote central nervous system neuroinflammation in progressive EAE. Nat Immunol. 2009; 10:958-964. [PubMed: 19684606]

18. Daneman R, Rescigno M. The gut immune barrier and the blood-brain barrier: are they so different? Immunity. 2009; 31:722-735. [PubMed: 19836264]

19. Larochelle C, Alvarez JI, Prat A. How do immune cells overcome the blood-brain barrier in multiple sclerosis? FEBS Lett. 2011; 585:3770-3780. [PubMed: 21550344]

20. Abbott NJ, Rönnbäck L, Hansson E. Astrocyte-endothelial interactions at the blood-brain barrier. Nature Reviews Neuroscience. 2006; 7:41-53.

21. Frank BT, Rossall JC, Caughey GH, Fang KC. Mast cell tissue inhibitor of metalloproteinase-1 is cleaved and inactivated extracellularly by alpha-chymase. J Immunol. 2001; 166:2783-2792. [PubMed: 11160345]

22. Alvarez JI, Cayrol R, Prat A. Disruption of central nervous system barriers in multiple sclerosis. Biochim Biophys Acta. 2011; 1812:252-264. [PubMed: 20619340] 
23. Tchougounova E. A Key Role for Mast Cell Chymase in the Activation of Pro-matrix Metalloprotease-9 and Pro-matrix Metalloprotease-2. J Biol Chem. 2004; 280:9291-9296. [PubMed: 15615702]

24. Johnson D, Seeldrayers PA, Weiner HL. The role of mast cells in demyelination. 1. Myelin proteins are degraded by mast cell proteases and myelin basic protein and P2 can stimulate mast cell degranulation. Brain Res. 1988; 444:195-198. [PubMed: 2451996]

25. Secor VH, Secor WE, Gutekunst CA, Brown MA. Mast cells are essential for early onset and severe disease in a murine model of multiple sclerosis. J Exp Med. 2000; 191:813-822. [PubMed: 10704463]

26. Modlin RL. Innate immunity: ignored for decades, but not forgotten. J Invest Dermatol. 2011; 132:882-886. [PubMed: 22158552]

27. Sayed BA, Walker ME, Brown MA. Cutting edge: mast cells regulate disease severity in a relapsing-remitting model of multiple sclerosis. J Immunol. 2011; 186:3294-3298. [PubMed: 21325623]

28. Kawai T, Akira S. The role of pattern-recognition receptors in innate immunity: update on Tolllike receptors. Nat Immunol. 2010; 11:373-384. [PubMed: 20404851]

29. Kumar H, Kawai T, Akira S. Pathogen recognition by the innate immune system. Int Rev Immunol. 2011; 30:16-34. [PubMed: 21235323]

30. Dimitriadou V, Pang X, Theoharides TC. Hydroxyzine inhibits experimental allergic encephalomyelitis (EAE) and associated brain mast cell activation. Int J Immunopharmacol. 2000; 22:673-684. [PubMed: 10884588]

31. Grahnert A, Grahnert A, Klein C, Schilling E, Wehrhahn J, Hauschildt S. Review: NAD +: a modulator of immune functions. Innate Immun. 2011; 17:212-233. [PubMed: 20388721]

32. Dietsch GN, Hinrichs DJ. The role of mast cells in the elicitation of experimental allergic encephalomyelitis. J Immunol. 1989; 142:1476-1481. [PubMed: 2465341]

33. Penberthy WT, Tsunoda I. The importance of NAD in multiple sclerosis. Curr Pharm Des. 2009; 15:64-99. [PubMed: 19149604]

34. Piconese $S$, et al. Mast cells counteract regulatory T-cell suppression through interleukin- 6 and OX40/OX40L axis toward Th17-cell differentiation. Blood. 2009; 114:2639-2648. [PubMed: 19643985]

35. Andersson A, et al. Pivotal advance: HMGB1 expression in active lesions of human and experimental multiple sclerosis. J Leukoc Biol. 2008; 84:1248-1255. [PubMed: 18644848]

36. Forward NA, Furlong SJ, Yang Y, Lin T-J, Hoskin DW. Mast cells down-regulate CD4+CD25+ T regulatory cell suppressor function via histamine $\mathrm{H} 1$ receptor interaction. The J Immunol. 2009; 183:3014-3022.

37. Quintana FJ, Farez MF, Izquierdo G, Lucas M, Cohen IR, Weiner HL. Antigen microarrays identify CNS-produced autoantibodies in RRMS. Neurology. 2012; 78:532-539. [PubMed: 22262743]

38. Quintana FJ, et al. Antigen microarrays identify unique serum autoantibody signatures in clinical and pathologic subtypes of multiple sclerosis. Proc Natl Acad Sci USA. 2008; 105:18889-18894. [PubMed: 19028871]

39. Walker ME, Hatfield JK, Brown MA. New insights into the role of mast cells in autoimmunity: Evidence for a common mechanism of action? Biochim Biophys Acta. 2012; 1822:57-65. [PubMed: 21354470]

40. Tsan M-F, Gao B. Heat shock proteins and immune system. J Leukoc Biol. 2009; 85:905-910. [PubMed: 19276179]

41. Gao H-M, Zhou H, Zhang F, Wilson BC, Kam W, Hong J-S. HMGB1 Acts on Microglia Mac1 to Mediate Chronic Neuroinflammation That Drives Progressive Neurodegeneration. J Neurosci. 2011; 31:081-1092.

42. Ivanov S, et al. A novel role for HMGB1 in TLR9-mediated inflammatory responses to CpGDNA. Blood. 2007; 110:970-1981.

43. Thériault JR, Mambula SS, Sawamura T, Stevenson MA, Calderwood SK. Extracellular HSP70 binding to surface receptors present on antigen presenting cells and endothelial/epithelial cells. FEBS Lett. 2005; 579:1951-1960. [PubMed: 15792802] 
44. Calderwood SK, Mambula SS, Gray PJ. Extracellular heat shock proteins in cell signaling and immunity. Ann NY Acad Sci. 2007; 1113:28-39. [PubMed: 17978280]

45. Wesch D, Peters C, Oberg H-H, Pietschmann K, Kabelitz D. Modulation of $\gamma \delta \mathrm{T}$ cell responses by TLR ligands. Cell Mol Life Sci. 2011; 68:2357-2370. [PubMed: 21560072]

46. Lünemann JD. Epstein-Barr virus in multiple sclerosis: a continuing conundrum. Neurology. 2012; 78:11-12. [PubMed: 22156986]

47. Blink SE, Miller SD. The contribution of $\gamma \delta \mathrm{T}$ cells to the pathogenesis of EAE and MS. Curr Mol Med. 2009; 9:15-22. [PubMed: 19199938]

48. Carding SR, Egan PJ. Gammadelta T cells: functional plasticity and heterogeneity. Nat Rev Immunol. 2002; 2:336-345. [PubMed: 12033739]

49. Reboldi A, et al. C-C chemokine receptor 6-regulated entry of TH-17 cells into the CNS through the choroid plexus is required for the initiation of EAE. Nat Immunol. 2009; 10:514-523. [PubMed: 19305396]

50. Carson MJ, Doose JM, Melchior B, Schmid CD, Ploix CC. CNS immune privilege: hiding in plain sight. Immunol Rev. 2006; 213:48-65. [PubMed: 16972896]

51. Axtell RC, Steinman L. Gaining entry to an uninflamed brain. Nat Immunol. 2009; 10:453-455. [PubMed: 19381137]

52. Ransohoff RM, Perry VH. Microglial physiology: unique stimuli, specialized responses. Annu Rev Immunol. 2009; 27:119-145. [PubMed: 19302036]

53. Kettenmann H, Hanisch U-K, Noda M, Verkhratsky A. Physiology of microglia. Physiol Rev. 2011; 91:461-553. [PubMed: 21527731]

54. Shrivastava K, Gonzalez P, Acarin L. The immune inhibitory complex CD200/CD200R is developmentally regulated in the mouse brain. J Comp Neurol. 201210.1002/cne.23062

55. Hoek RM. Down-regulation of the macrophage lineage through interaction with OX2 (CD200). Science. 2000; 290:1768-1771. [PubMed: 11099416]

56. Ponomarev ED, Veremeyko T, Barteneva N, Krichevsky AM, Weiner HL. MicroRNA-124 promotes microglia quiescence and suppresses EAE by deactivating macrophages via the C/EBPa-PU. 1 pathway. Nat Med. 2011; 17:64-70. [PubMed: 21131957]

57. Boulanger LM. Immune proteins in brain development and synaptic plasticity. Neuron. 2009; 64:93-109. [PubMed: 19840552]

58. Ueno H, Palucka AK, Banchereau J. The expanding family of dendritic cell subsets. Nat Biotechnol. 2010; 28:813-815. [PubMed: 20697407]

59. Wu L, Liu Y-J. Development of dendritic-cell lineages. Immunity. 2007; 26:741-750. [PubMed: 17582346]

60. Wu H-Y, et al. In vivo induction of Tr1 cells via mucosal dendritic cells and AHR signaling. PLoS ONE. 2011; 6:e23618. [PubMed: 21886804]

61. Quintana FJ, et al. Control of Treg and TH17 cell differentiation by the aryl hydrocarbon receptor. Nature. 2008; 453:65-71. [PubMed: 18362915]

62. Severson C, Hafler DA. T-cells in multiple sclerosis. Results Probl Cell Differ. 2010; 51:75-98. [PubMed: 19582415]

63. Barreira da Silva R, Münz C. Natural killer cell activation by dendritic cells: balancing inhibitory and activating signals. Cell Mol Life Sci. 2011; 68:3505-3518. [PubMed: 21861182]

64. Greter M, et al. Dendritic cells permit immune invasion of the CNS in an animal model of multiple sclerosis. Nat Med. 2005; 11:328-334. [PubMed: 15735653]

65. Miller SD, McMahon EJ, Schreiner B, Bailey SL. Antigen presentation in the CNS by myeloid dendritic cells drives progression of relapsing experimental autoimmune encephalomyelitis. Ann NY Acad Sci. 2007; 1103:179-191. [PubMed: 17376826]

66. McMahon EJ, Bailey SL, Castenada CV, Waldner H, Miller SD. Epitope spreading initiates in the CNS in two mouse models of multiple sclerosis. Nat Med. 2005; 11:335-339. [PubMed: 15735651]

67. Murugaiyan G, Mittal A, Weiner HL. Increased osteopontin expression in dendritic cells amplifies IL-17 production by CD4+ T cells in experimental autoimmune encephalomyelitis and in multiple sclerosis. J Immunol. 2008; 181:7480-7488. [PubMed: 19017937] 
68. Murugaiyan G, Mittal A, Weiner HL. Identification of an IL-27/osteopontin axis in dendritic cells and its modulation by IFN-gamma limits IL-17-mediated autoimmune inflammation. Proc Natl Acad Sci USA. 2010; 107:11495-11500. [PubMed: 20534530]

69. Quintana FJ, et al. An endogenous aryl hydrocarbon receptor ligand acts on dendritic cells and T cells to suppress experimental autoimmune encephalomyelitis. Proc Natl Acad Sci USA. 2010; 107:20768-20773. [PubMed: 21068375]

70. Bailey SL, Schreiner B, McMahon EJ, Miller SD. CNS myeloid DCs presenting endogenous myelin peptides "preferentially" polarize CD4+ TH-17 cells in relapsing EAE. Nat Immunol. 2007; 8:172-180. [PubMed: 17206145]

71. Stasiolek M, et al. Impaired maturation and altered regulatory function of plasmacytoid dendritic cells in multiple sclerosis. Brain. 2006; 129:1293-1305. [PubMed: 16513684]

72. Morandi B, et al. Role of natural killer cells in the pathogenesis and progression of multiple sclerosis. Pharmacol Res. 2008; 57:1-5. [PubMed: 18182304]

73. De Jager PL, et al. Cytometric profiling in multiple sclerosis uncovers patient population structure and a reduction of CD8low cells. Brain. 2008; 131:1701-1711. [PubMed: 18567923]

74. Takahashi K, Aranami T, Endoh M, Miyake S, Yamamura T. The regulatory role of natural killer cells in multiple sclerosis. Brain. 2004; 127:1917-1927. [PubMed: 15229129]

75. Lünemann A, et al. Human NK cells kill resting but not activated microglia via NKG2D-and NKp46-mediated recognition. J Immunol. 2008; 181:6170-6177. [PubMed: 18941207]

76. Zhang H, Bennett JL, Verkman AS. Ex vivo spinal cord slice model of neuromyelitis optica reveals novel immunopathogenic mechanisms. Ann Neurol. 2011; 70:943-954. [PubMed: 22069219]

77. Shi FD, Takeda K, Akira S, Sarvetnick N, Ljunggren HG. IL-18 directs autoreactive T cells and promotes autodestruction in the central nervous system via induction of IFN-gamma by NK cells. J Immunol. 2000; 165:3099-3104. [PubMed: 10975822]

78. Matsumoto Y, et al. Role of natural killer cells and TCR gamma delta T cells in acute autoimmune encephalomyelitis. Eur J Immunol. 1998; 28:1681-1688. [PubMed: 9603475]

79. Vollmer TL, Liu R, Price M, Rhodes S, La Cava A, Shi F-D. Differential effects of IL-21 during initiation and progression of autoimmunity against neuroantigen. J Immunol. 2005; 174:26962701. [PubMed: 15728477]

80. Hammarberg $\mathrm{H}$, et al. Neuroprotection by encephalomyelitis: rescue of mechanically injured neurons and neurotrophin production by CNS-infiltrating T and natural killer cells. 2000; 20:5283-5291.

81. Bielekova B, et al. Regulatory CD56bright natural killer cells mediate immunomodulatory effects of IL-2Ra-targeted therapy (daclizumab) in multiple sclerosis. Proc Natl Acad Sci USA. 2006; 103:5941-5946. [PubMed: 16585503]

82. Lünemann A, et al. Impaired IFN- $\gamma$ production and proliferation of $\mathrm{NK}$ cells in multiple sclerosis. Int Immunol. 2011; 23:139-148. [PubMed: 21212154]

83. Takahashi K, et al. Natural killer type 2 bias in remission of multiple sclerosis. J Clin Invest. 2001; 107:R23-29. [PubMed: 11238569]

84. Mayo L, Stein R. Characterization of LPS and interferon-gamma triggered activation-induced cell death in N9 and primary microglial cells: induction of the mitochondrial gateway by nitric oxide. Cell Death Differ. 2007; 14:183-186. [PubMed: 16778833]

85. Ponomarev ED, Dittel BN. Gamma delta T cells regulate the extent and duration of inflammation in the central nervous system by a Fas ligand-dependent mechanism. J Immunol. 2005; 174:46784687. [PubMed: 15814692]

86. Perry VH, Nicoll JAR, Holmes C. Microglia in neurodegenerative disease. Nat Rev Neurol. 2010; 6:193-201. [PubMed: 20234358]

87. Lindsberg PJ, Strbian D, Karjalainen-Lindsberg M-L. Mast cells as early responders in the regulation of acute blood-brain barrier changes after cerebral ischemia and hemorrhage. J Cereb Blood Flow Metab. 2010; 30:689-702. [PubMed: 20087366]

88. Ajami B, Bennett JL, Krieger C, McNagny KM, Rossi FMV. Infiltrating monocytes trigger EAE progression, but do not contribute to the resident microglia pool. Nat Neurosci. 2011; 14:11421149. [PubMed: 21804537] 
89. Brandes M, Willimann K, Moser B. Professional antigen-presentation function by human gammadelta T Cells. Science. 2005; 309:264-268. [PubMed: 15933162]

90. Ibrahim MZ, Reder AT, Lawand R, Takash W, Sallouh-Khatib S. The mast cells of the multiple sclerosis brain. J Neuroimmunol. 1996; 70:131-138. [PubMed: 8898721]

91. Ness-Schwickerath KJ, Morita CT. Regulation and function of IL-17A- and IL-22-producing $\gamma \delta \mathrm{T}$ cells. Cell Mol Life Sci. 2011; 68:2371-2390. [PubMed: 21573786]

92. Rozniecki JJ, Hauser SL, Stein M, Lincoln R, Theoharides TC. Elevated mast cell tryptase in cerebrospinal fluid of multiple sclerosis patients. Ann Neurol. 1995; 37:63-66. [PubMed: 7818259]

93. Iarosh OO, Kanevs'ka SA. The characteristics of the blood histamine indices and of the pathomorphological changes in the gastric mucosa of patients with multiple sclerosis. Lik Sprava. 1992; 1:75-76. [PubMed: 1364615]

94. Wucherpfennig KW, Newcombe J, Li H, Keddy C, Cuzner ML, Hafler DA. Gamma delta T-cell receptor repertoire in acute multiple sclerosis lesions. Proc Natl Acad Sci USA. 1992; 89:45884592. [PubMed: 1374907]

95. Lock C, et al. Gene-microarray analysis of multiple sclerosis lesions yields new targets validated in autoimmune encephalomyelitis. Nat Med. 2002; 8:500-508. [PubMed: 11984595]

96. Kress E, Hedges JF, Jutila MA. Distinct gene expression in human Vdelta1 and Vdelta2 gammadelta T cells following non-TCR agonist stimulation. Mol Immunol. 2006; 43:2002-2011. [PubMed: 16423401]

97. Shimonkevitz R, Colburn C, Burnham JA, Murray RS, Kotzin BL. Clonal expansions of activated gamma/delta T cells in recent-onset multiple sclerosis. Proc Natl Acad Sci USA. 1993; 90:923927. [PubMed: 8430106]

98. Mix E, Olsson T, Correale J, Kostulas V, Link H. CD4+, CD8+, and CD4- CD8- T cells in CSF and blood of patients with multiple sclerosis and tension headache. Scand J Immunol. 1990; 31:493-501. [PubMed: 1970668]

99. Stinissen $P$, et al. Increased frequency of gamma delta $\mathrm{T}$ cells in cerebrospinal fluid and peripheral blood of patients with multiple sclerosis. Reactivity, cytotoxicity, and $\mathrm{T}$ cell receptor $\mathrm{V}$ gene rearrangements. J Immunol. 1995; 154:4883-4894. [PubMed: 7722338]

100. Rinaldi L. Longitudinal analysis of immune cell phenotypes in early stage multiple sclerosis: distinctive patterns characterize MRI-active patients. Brain. 2006; 129:1993-2007. [PubMed: 16870883]

101. Chen Z, Freedman MS. Correlation of specialized CD16+ $\gamma \delta$ T cells with disease course and severity in multiple sclerosis. J Neuroimmunol. 2008; 194:147-152. [PubMed: 18155780]

102. Berzins SP, Smyth MJ, Baxter AG. Presumed guilty: natural killer T cell defects and human disease. Nat Rev Immunol. 2011; 11:131-142. [PubMed: 21267014]

103. Podbielska M, Hogan E. Molecular and immunogenic features of myelin lipids: incitants or modulators of multiple sclerosis? Multiple Sclerosis. 2009; 15:1011-1029. [PubMed: 19692432]

104. Mars LT, et al. Invariant NKT cells regulate experimental autoimmune encephalomyelitis and infiltrate the central nervous system in a CD1d-independent manner. J Immunol. 2008; 181:2321-2329. [PubMed: 18684921]

105. Sonoda KH, Faunce DE, Taniguchi M, Exley M, Balk S, Stein-Streilein J. NK T cell-derived IL-10 is essential for the differentiation of antigen-specific T regulatory cells in systemic tolerance. J Immunol. 2001; 166:42-50. [PubMed: 11123275]

106. Pál E, Tabira T, Kawano T, Taniguchi M, Miyake S, Yamamura T. Costimulation-dependent modulation of experimental autoimmune encephalomyelitis by ligand stimulation of $\mathrm{V}$ alpha 14 NK T cells. J Immunol. 2001; 166:662-668. [PubMed: 11123351]

107. Mars LT, et al. Cutting edge: Va14-Ja281 NKT cells naturally regulate experimental autoimmune encephalomyelitis in nonobese diabetic mice. J Immunol. 2002; 168:6007-6011. [PubMed: 12055208]

108. Singh AK, et al. Natural killer T cell activation protects mice against experimental autoimmune encephalomyelitis. J Exp Med. 2001; 194:1801-1811. [PubMed: 11748281] 
109. O'Keeffe J, et al. T-cells expressing natural killer (NK) receptors are altered in multiple sclerosis and responses to alpha-galactosylceramide are impaired. J Neurol Sci. 2008; 275:22-28. [PubMed: 18706662]

110. Araki M, Kondo T, Gumperz JE, Brenner MB, Miyake S, Yamamura T. Th2 bias of CD4+ NKT cells derived from multiple sclerosis in remission. Int Immunol. 2003; 15:279-288. [PubMed: 12578858]

111. Gausling R, Trollmo C, Hafler DA. Decreases in interleukin-4 secretion by invariant CD4 CD8 Va24JaQ T cells in peripheral blood of patients with relapsing remitting multiple sclerosis. Clin Immunol. 2001; 98:11-17. [PubMed: 11141321]

112. Gigli G, Caielli S, Cutuli D, Falcone M. Innate immunity modulates autoimmunity: type 1 interferon-beta treatment in multiple sclerosis promotes growth and function of regulatory invariant natural killer T cells through dendritic cell maturation. Immunology. 2007; 122:409417. [PubMed: 17617156]

113. Gandhi R, Weiner HL. Immune System, Innate, Overview. 2012:1-14.

114. Nimmerjahn A, Kirchhoff F, Helmchen F. Resting microglial cells are highly dynamic surveillants of brain parenchyma in vivo. Science. 2005; 308:1314-1318. [PubMed: 15831717]

115. Davalos D. ATP mediates rapid microglial response to local brain injury in vivo. Nat Neurosci. 2005; 8:752-758. [PubMed: 15895084]

116. Anderson AC, et al. Promotion of tissue inflammation by the immune receptor Tim-3 expressed on innate immune cells. Science. 2007; 318:1141-1143. [PubMed: 18006747]

117. Mizutani M, Pino PA, Saederup N, Charo IF, Ransohoff R, Cardona A. The fractalkine receptor but not CCR2 is present on microglia from embryonic development throughout adulthood. J Immunol. 2012; 188:28-36.

118. Saederup N, et al. Selective chemokine receptor usage by central nervous system myeloid cells in CCR2-Red fluorescent protein knock-in mice. PLoS ONE. 2010; 5:e13693. [PubMed: 21060874]

119. Sato N, et al. Functional characterization of NK1. 1 + Ly-6C+ cells. Immunol Lett. 1996; 54:5-9. [PubMed: 9030975]

120. Chiossone L, Chaix J, Fuseri N, Roth C, Vivier E, Walzer T. Maturation of mouse NK cells is a 4-stage developmental program. Blood. 2009; 113:5488-5496. [PubMed: 19234143]

121. Prinz M, Priller J. Tickets to the brain: role of CCR2 and CX3CR1 in myeloid cell entry in the CNS. J Neuroimmunol. 2010; 224:80-84. [PubMed: 20554025]

122. Horikoshi Y, et al. Human GLUT5 immunolabeling is useful for evaluating microglial status in neuropathological study using paraffin sections. Acta Neuropathol. 2003; 105:157-162. [PubMed: 12536226]

123. Bédard A, Tremblay P, Chernomoretz A, Vallières L. Identification of genes preferentially expressed by microglia and upregulated during cuprizone-induced inflammation. Glia. 2007; 55:777-789. [PubMed: 17285589]

124. Trebst C, et al. CCR1+/CCR5+ mononuclear phagocytes accumulate in the central nervous system of patients with multiple sclerosis. Am J Pathol. 2001; 159:1701-1710. [PubMed: 11696431]

125. Peterson JW, Bo L, Mörk S, Chang A, Trapp BD. Transected neurites, apoptotic neurons, and reduced inflammation in cortical multiple sclerosis lesions. Ann Neurol. 2001; 50:389-400. [PubMed: 11558796]

126. Moll NM, et al. Cortical demyelination in PML and MS: Similarities and differences. Neurology. 2008; 70:336-343. [PubMed: 17914063]

127. Kutzelnigg A, et al. Cortical demyelination and diffuse white matter injury in multiple sclerosis. Brain. 2005; 128:2705-2712. [PubMed: 16230320]

128. Satoh J-I, et al. Neuromyelitis optica/Devic's disease: Gene expression profiling of brain lesions. Neuropathology. 2008; 28:561-576. [PubMed: 18410276]

129. Bradl M, et al. Neuromyelitis optica: Pathogenicity of patient immunoglobulin in vivo. Ann Neurol. 2009; 66:630-643. [PubMed: 19937948]

130. Heppner FL, et al. Experimental autoimmune encephalomyelitis repressed by microglial paralysis. Nat Med. 2005; 11:146-152. [PubMed: 15665833] 
131. Tran EH, Hoekstra K, van Rooijen N, Dijkstra CD, Owens T. Immune invasion of the central nervous system parenchyma and experimental allergic encephalomyelitis, but not leukocyte extravasation from blood, are prevented in macrophage-depleted mice. J Immunol. 1998; 161:3767-3775. [PubMed: 9759903]

132. Huizinga R, et al. Phagocytosis of neuronal debris by microglia is associated with neuronal damage in multiple sclerosis. Glia. 2012; 60:422-431. [PubMed: 22161990]

133. Bauer J, Sminia T, Wouterlood FG, Dijkstra CD. Phagocytic activity of macrophages and microglial cells during the course of acute and chronic relapsing experimental autoimmune encephalomyelitis. J Neurosci Res. 1994; 38:365-375. [PubMed: 7932870]

134. Katz-Levy Y, et al. Temporal development of autoreactive Th1 responses and endogenous presentation of self myelin epitopes by central nervous system-resident APCs in Theiler's virusinfected mice. J Immunol. 2000; 165:5304-5314. [PubMed: 11046065]

135. Mildner A, et al. CCR2+Ly-6Chi monocytes are crucial for the effector phase of autoimmunity in the central nervous system. Brain. 2009; 132:2487-2500. [PubMed: 19531531]

136. Fife BT, Huffnagle GB, Kuziel WA, Karpus WJ. CC chemokine receptor 2 is critical for induction of experimental autoimmune encephalomyelitis. J Exp Med. 2000; 192:899-905. [PubMed: 10993920]

137. King IL, Dickendesher TL, Segal BM. Circulating Ly-6C+ myeloid precursors migrate to the CNS and play a pathogenic role during autoimmune demyelinating disease. Blood. 2009; 113:3190-3197. [PubMed: 19196868]

138. Izikson L, Klein RS, Charo IF, Weiner HL, Luster AD. Resistance to experimental autoimmune encephalomyelitis in mice lacking the CC chemokine receptor (CCR)2. J Exp Med. 2000; 192:1075-1080. [PubMed: 11015448]

139. Kotter MR, Zhao C, van Rooijen N, Franklin RJM. Macrophage-depletion induced impairment of experimental CNS remyelination is associated with a reduced oligodendrocyte progenitor cell response and altered growth factor expression. Neurobiol Dis. 2005; 18:166-175. [PubMed: 15649707]

140. Kotter MR, Setzu A, Sim FJ, van Rooijen N, Franklin RJ. Macrophage depletion impairs oligodendrocyte remyelination following lysolecithin-induced demyelination. Glia. 2001; 35:204-212. [PubMed: 11494411]

141. Stadelmann C, Kerschensteiner M, Misgeld T, Brück W, Hohlfeld R, Lassmann H. BDNF and gp145trkB in multiple sclerosis brain lesions: neuroprotective interactions between immune and neuronal cells? Brain. 2002; 125:75-85. [PubMed: 11834594]

142. Magnus T, et al. Microglial expression of the B7 family member B7 homolog 1 confers strong immune inhibition: implications for immune responses and autoimmunity in the CNS. J Neurosci. 2005; 25:2537-2546. [PubMed: 15758163]

143. Duncan DS, Miller SD. CNS expression of B7-H1 regulates pro-inflammatory cytokine production and alters severity of Theiler's virus-induced demyelinating disease. PLoS ONE. 2011; 6:e18548. [PubMed: 21494618]

144. Kimelberg HK. Functions of mature mammalian astrocytes: a current view. Neuroscientist. 2010; 16:79-106. [PubMed: 20236950]

145. Yang Y, et al. Molecular comparison of GLT1+ and ALDH1L1+ astrocytes in vivo in astroglial reporter mice. Glia. 2011; 59:200-207. [PubMed: 21046559]

146. Pfrieger FW, Slezak M. Genetic approaches to study glial cells in the rodent brain. Glia. 2012; 60:681-701. [PubMed: 22162024]

147. Cahoy JD, et al. A transcriptome database for astrocytes, neurons, and oligodendrocytes: a new resource for understanding brain development and function. J Neurosci. 2008; 28:264-278. [PubMed: 18171944]

148. Foo LC, et al. Development of a method for the purification and culture of rodent astrocytes. Neuron. 2011; 71:799-811. [PubMed: 21903074]

149. Saura J. Microglial cells in astroglial cultures: a cautionary note. J Neuroinflammation. 2007; 4:26. [PubMed: 17937799]

150. Nair A, Frederick TJ, Miller SD. Astrocytes in multiple sclerosis: a product of their environment. Cell Mol Life Sci. 2008; 65:2702-2720. [PubMed: 18516496] 
151. Hinson SR, et al. Molecular outcomes of neuromyelitis optica (NMO)-IgG binding to aquaporin-4 in astrocytes. Proc Natl Acad Sci USA. 2012; 109:1245-1250. [PubMed: 22128336]

152. Fujihara K. Neuromyelitis optica and astrocytic damage in its pathogenesis. J Neurol Sci. 2011; 306:183-187. [PubMed: 21396661]

153. Kang Z, et al. Astrocyte-restricted ablation of interleukin-17-induced Act1-mediated signaling ameliorates autoimmune encephalomyelitis. Immunity. 2010; 32:414-425. [PubMed: 20303295]

154. Levy H, Assaf Y, Frenkel D. Characterization of brain lesions in a mouse model of progressive multiple sclerosis. Exp Neurol. 2010; 226:148-158. [PubMed: 20736006]

155. Titeux M, Galou M, Gomes FCA, Dormont D, Neto VM, Paulin D. Differences in the activation of the GFAP gene promoter by prion and viral infections. Brain Res Mol Brain Res. 2002; 109:119-127. [PubMed: 12531521]

156. Skripuletz T, et al. Cerebellar cortical demyelination in the murine cuprizone model. Brain Pathol. 2010; 20:301-312. [PubMed: 19371354]

157. Bush TG, et al. Leukocyte infiltration, neuronal degeneration, and neurite outgrowth after ablation of scar-forming, reactive astrocytes in adult transgenic mice. Neuron. 1999; 23:297-308. [PubMed: 10399936]

158. Faulkner JR, Herrmann JE, Woo MJ, Tansey KE, Doan NB, Sofroniew MV. Reactive astrocytes protect tissue and preserve function after spinal cord injury. J Neurosci. 2004; 24:2143-2155. [PubMed: 14999065]

159. Voskuhl RR, et al. Reactive astrocytes form scar-like perivascular barriers to leukocytes during adaptive immune inflammation of the CNS. J Neurosci. 2009; 29:11511-11522. [PubMed: 19759299]

160. Toft-Hansen H, Füchtbauer L, Owens T. Inhibition of reactive astrocytosis in established experimental autoimmune encephalomyelitis favors infiltration by myeloid cells over $\mathrm{T}$ cells and enhances severity of disease. Glia. 2011; 59:166-176. [PubMed: 21046558]

161. Farina C, Aloisi F, Meinl E. Astrocytes are active players in cerebral innate immunity. Trends Immunol. 2007; 28:138-145. [PubMed: 17276138]

162. Calderon TM, et al. A role for CXCL12 (SDF-1a) in the pathogenesis of multiple sclerosis: regulation of CXCL12 expression in astrocytes by soluble myelin basic protein. $\mathrm{J}$ Neuroimmunol. 2006; 177:27-39. [PubMed: 16782208]

163. Alter A, et al. Determinants of human B cell migration across brain endothelial cells. J Immunol. 2003; 170:4497-4505. [PubMed: 12707326]

164. Han Y, He T, Huang DR, Pardo CA, Ransohoff RM. TNF-a mediates SDF-1a induced NF- $к B$ activation and cytotoxic effects in primary astrocytes. J Clin Invest. 2001; 108:425-435. [PubMed: 11489936]

165. Bajetto A, et al. Stromal cell-derived factor-1a induces astrocyte proliferation through the activation of extracellular signal-regulated kinases 1/2 pathway. J Neurochem. 2001; 77:12261236. [PubMed: 11389173]

166. Patel JR, McCandless EE, Dorsey D, Klein RS. CXCR4 promotes differentiation of oligodendrocyte progenitors and remyelination. Proc Natl Acad Sci USA. 2010; 107:1106211067. [PubMed: 20534485]

167. Dziembowska M, Tham TN, Lau P, Vitry S, Lazarini F, Dubois-Dalcq M. A role for CXCR4 signaling in survival and migration of neural and oligodendrocyte precursors. Glia. 2005; 50:258-269. [PubMed: 15756692]

168. Banisadr G, et al. The role of CXCR4 signaling in the migration of transplanted oligodendrocyte progenitors into the cerebral white matter. Neurobiol Dis. 2011; 44:19-27. [PubMed: 21684336]

169. Zhang K, et al. HIV-induced metalloproteinase processing of the chemokine stromal cell derived factor-1 causes neurodegeneration. Nat Neurosci. 2003; 6:1064-1071. [PubMed: 14502291]

170. Zeinstra E, Wilczak N, Streefland C, Keyser JD. Astrocytes in chronic active multiple sclerosis plaques express MHC class II molecules. Neuroreport. 2000; 11:89-91. [PubMed: 10683836]

171. Kort JJ, Kawamura K, Fugger L, Weissert R, Forsthuber TG. Efficient presentation of myelin oligodendrocyte glycoprotein peptides but not protein by astrocytes from HLA-DR2 and HLADR4 transgenic mice. J Neuroimmunol. 2006; 173:23-34. [PubMed: 16386804] 
172. Chastain EML, Duncan DS, Rodgers JM, Miller SD. The role of antigen presenting cells in multiple sclerosis. Biochim Biophys Acta. 2011; 1812:265-274. [PubMed: 20637861]

173. Lee SC, Moore GR, Golenwsky G, Raine CS. Multiple sclerosis: a role for astroglia in active demyelination suggested by class II MHC expression and ultrastructural study. J Neuropathol Exp Neurol. 1990; 49:122-136. [PubMed: 2307980]

174. Magnus T, Chan A, Linker RA, Toyka KV, Gold R. Astrocytes are less efficient in the removal of apoptotic lymphocytes than microglia cells: implications for the role of glial cells in the inflamed central nervous system. J Neuropathol Exp Neurol. 2002; 61:760-766. [PubMed: 12230322]

175. Aloisi F, Serafini B, Adorini L. Glia-T cell dialogue. J Neuroimmunol. 2000; 107:111-117. [PubMed: 10854644]

176. Gimenez MAT, Sim JE, Russell JH. TNFR1-dependent VCAM-1 expression by astrocytes exposes the CNS to destructive inflammation. J Neuroimmunol. 2004; 151:116-125. [PubMed: 15145610]

177. Sobel RA, Mitchell ME, Fondren G. Intercellular adhesion molecule-1 (ICAM-1) in cellular immune reactions in the human central nervous system. Am J Pathol. 1990; 136:1309-1316. [PubMed: 1972610]

178. Bechmann I, et al. Astrocyte-induced T cell elimination is CD95 ligand dependent. J Neuroimmunol. 2002; 132:60-65. [PubMed: 12417434]

179. Bechmann I, Mor G, Nilsen J, Eliza M, Nitsch R, Naftolin F. FasL (CD95L, Apo1L) is expressed in the normal rat and human brain: evidence for the existence of an immunological brain barrier. Glia. 1999; 27:62-74. [PubMed: 10401633]

180. Pender MP, Nguyen KB, McCombe PA, Kerr JFR. Apoptosis in the nervous system in experimental allergic encephalomyelitis. J Neurol Sci. 1991; 104:81-87. [PubMed: 1717664]

181. Xiao BG, Xu LY, Yang JS, Huang YM, Link H. An alternative pathway of nitric oxide production by rat astrocytes requires specific antigen and T cell contact. Neurosci Lett. 2000; 283:53-56. [PubMed: 10729632]

182. Hara H, Nanri Y, Tabata E, Mitsutake S, Tabira T. Identification of astrocyte-derived immune suppressor factor that induces apoptosis of autoreactive T cells. J Neuroimmunol. 2011; 233:135-146. [PubMed: 21277028]

183. Didier N, Romero IA, Créminon C, Wijkhuisen A, Grassi J, Mabondzo A. Secretion of interleukin-1beta by astrocytes mediates endothelin- 1 and tumour necrosis factor-alpha effects on human brain microvascular endothelial cell permeability. J Neurochem. 2003; 86:246-254. [PubMed: 12807444]

184. Liuzzi GM, Latronico T, Fasano A, Carlone G, Riccio P. Interferon-beta inhibits the expression of metalloproteinases in rat glial cell cultures: implications for multiple sclerosis pathogenesis and treatment. Mult Scler. 2004; 10:290-297. [PubMed: 15222694]

185. Mohan H, et al. Extracellular matrix in multiple sclerosis lesions: Fibrillar collagens, biglycan and decorin are upregulated and associated with infiltrating immune cells. Brain Pathol. 2010; 20:966-975. [PubMed: 20456365]

186. Cuzner ML, Gveric D, Strand C, Loughlin AJ, Paemen L, Opdenakker G, Newcombe J. The expression of tissue-type plasminogen activator, matrix metalloproteases and endogenous inhibitors in the central nervous system in multiple sclerosis: comparison of stages in lesion evolution. J Neuropathol Exp Neurol. 1996; 55:1194-1204. [PubMed: 8957442]

187. Gardner J, Ghorpade A. Tissue inhibitor of metalloproteinase (TIMP)-1: the TIMPed balance of matrix metalloproteinases in the central nervous system. J Neurosci Res. 2003; 74:801-806. [PubMed: 14648584]

188. Holley JE, Gveric D, Newcombe J, Cuzner ML, Gutowski NJ. Astrocyte characterization in the multiple sclerosis glial scar. Neuropathol Appl Neurobiol. 2003; 29:434-444. [PubMed: 14507335]

189. Sofroniew MV. Molecular dissection of reactive astrogliosis and glial scar formation. Trends Neurosci. 2009; 32:638. [PubMed: 19782411]

190. Göritz C, Dias DO, Tomilin N, Barbacid M, Shupliakov O, Frisén J. A pericyte origin of spinal cord scar tissue. Science. 2011; 333:238-242. [PubMed: 21737741] 
191. Rolls A, Shechter R, Schwartz M. The bright side of the glial scar in CNS repair. Nat Rev Neurosci. 2009; 10:235-241. [PubMed: 19229242]

192. Bannerman P, Hahn A, Soulika A, Gallo V, Pleasure D. Astrogliosis in EAE spinal cord: derivation from radial glia, and relationships to oligodendroglia. Glia. 2007; 55:57-64. [PubMed: 17009237]

193. Goddard DR, Berry M, Butt AM. In vivo actions of fibroblast growth factor-2 and insulin-like growth factor-I on oligodendrocyte development and myelination in the central nervous system. J Neurosci Res. 1999; 57:74-85. [PubMed: 10397637]

194. Clemente D, Ortega MC, Arenzana FJ, de Castro F. FGF-2 and Anosmin-1 are selectively expressed in different types of multiple sclerosis lesions. J Neurosci. 2011; 31:14899-14909. [PubMed: 22016523]

195. Silver J, Miller JH. Regeneration beyond the glial scar. Nat Rev Neurosci. 2004; 5:146-156. [PubMed: 14735117]

196. Asher RA, et al. Neurocan is upregulated in injured brain and in cytokine-treated astrocytes. $\mathrm{J}$ Neurosci. 2000; 20:2427-2438. [PubMed: 10729323]

197. Sobel RA, Ahmed AS. White matter extracellular matrix chondroitin sulfate/dermatan sulfate proteoglycans in multiple sclerosis. J Neuropathol Exp Neurol. 2001; 60:1198-1207. [PubMed: 11764092]

198. Haist V, Ulrich R, Kalkuhl A, Deschl U, Baumgärtner W. Distinct spatio-temporal extracellular matrix accumulation within demyelinated spinal cord lesions in Theiler's murine encephalomyelitis. Brain Pathology. 2011; 22:188-204. [PubMed: 21767322]

199. Liu J-Q, et al. CD24 on the resident cells of the central nervous system enhances experimental autoimmune encephalomyelitis. J Immunol. 2007; 178:6227-6235. [PubMed: 17475850]

200. Miljkovic D, Timotijević G, Stojković MM. Astrocytes in the tempest of multiple sclerosis. FEBS Lett. 2011; 585:3781-3788. [PubMed: 21443873]

201. Trajkovic V, et al. Astrocyte-induced regulatory T cells mitigate CNS autoimmunity. Glia. 2004; 47:168-179. [PubMed: 15185395]

202. Zhu C, Anderson AC, Kuchroo VK. TIM-3 and its regulatory role in immune responses. Curr Top Microbiol Immunol. 2011; 350:1-15. [PubMed: 20700701]

203. Tan L, Gordon KB, Mueller JP, Matis LA, Miller SD. Presentation of proteolipid protein epitopes and B7-1-dependent activation of encephalitogenic T cells by IFN-gamma-activated SJL/J astrocytes. J Immunol. 1998; 160:4271-4279. [PubMed: 9574529]

204. Miljkovic D, et al. Astrocytes stimulate interleukin-17 and interferon-gamma production in vitro. J Neurosci Res. 2007; 85:3598-3606. [PubMed: 17969033]

205. Saikali P, Antel JP, Pittet CL, Newcombe J, Arbour N. Contribution of astrocyte-derived IL-15 to CD8 T cell effector functions in multiple sclerosis. J Immunol. 2010; 185:5693-5703. [PubMed: 20926794]

206. Almolda B, González B, Castellano B. Antigen presentation in EAE: role of microglia, macrophages and dendritic cells. Front Biosci. 2011; 16:1157-1171. [PubMed: 21196224]

207. Zhou Y, et al. IL-9 promotes Th17 cell migration into the central nervous system via CC chemokine ligand-20 produced by astrocytes. J Immunol. 2011; 186:4415-4421. [PubMed: 21346235]

208. Krumbholz M, et al. BAFF is produced by astrocytes and up-regulated in multiple sclerosis lesions and primary central nervous system lymphoma. J Exp Med. 2005; 201:195-200.

[PubMed: 15642740]

209. Krumbholz M, et al. Interferon-beta increases BAFF levels in multiple sclerosis: implications for B cell autoimmunity. Brain. 2008; 131:1455-1463. [PubMed: 18474519]

210. Thangarajh M, Gomes A, Masterman T, Hillert J, Hjelmström P. Expression of B-cell-activating factor of the TNF family (BAFF) and its receptors in multiple sclerosis. J Neuroimmunol. 2004; 152:183-190. [PubMed: 15223251]

211. Saikali P, Cayrol R, Vincent T. Anti-aquaporin-4 auto-antibodies orchestrate the pathogenesis in neuromyelitis optica. Autoimmun Rev. 2009; 9:132-135. [PubMed: 19389490] 
212. Kinoshita M, et al. Anti-aquaporin-4 antibody induces astrocytic cytotoxicity in the absence of CNS antigen-specific T cells. Biochem Biophys Res Commun. 2010; 394:205-210. [PubMed: 20188706]

213. Aloisi F, Penna G, Cerase J, Menéndez Iglesias B, Adorini L. IL-12 production by central nervous system microglia is inhibited by astrocytes. J Immunol. 1997; 159:1604-1612. [PubMed: 9257819]

214. Min K-J, Yang M-S, Kim S-U, Jou I, Joe E-H. Astrocytes induce hemeoxygenase-1 expression in microglia: a feasible mechanism for preventing excessive brain inflammation. J Neurosci. 2006; 26:1880-1887. [PubMed: 16467537]

215. DeWitt DA, Perry G, Cohen M, Doller C, Silver J. Astrocytes regulate microglial phagocytosis of senile plaque cores of Alzheimer's disease. Exp Neurol. 1998; 149:329-340. [PubMed: 9500964]

216. Ambrosini E, et al. Astrocytes produce dendritic cell-attracting chemokines in vitro and in multiple sclerosis lesions. J Neuropathol Exp Neurol. 2005; 64:706-715. [PubMed: 16106219]

217. Hao J, et al. Central nervous system (CNS)-resident natural killer cells suppress Th17 responses and CNS autoimmune pathology. J Exp Med. 2010; 207:1907-1921. [PubMed: 20696699]

218. Moodley K, Angel CE, Glass M, Graham ES. Real-time profiling of NK cell killing of human astrocytes using xCELLigence technology. J Neurosci Methods. 2011; 200:173-180. [PubMed: 21781988]

219. Seeldrayers PA, Levin LA, Johnson D. Astrocytes support mast cell viability in vitro. J Neuroimmunol. 1992; 36:239-243. [PubMed: 1370670]

220. Kim DY, Jeoung D, Ro JY. Signaling pathways in the activation of mast cells cocultured with astrocytes and colocalization of both cells in experimental allergic encephalomyelitis. J Immunol. 2010; 185:273-283. [PubMed: 20511559]

221. Kim D-Y, Hong GU, Ro JY. Signal pathways in astrocytes activated by cross-talk between of astrocytes and mast cells through CD40-CD40L. J Neuroinflammation. 2011; 8:25. [PubMed: 21410936]

222. Freedman MS, D’Souza S, Antel JP. $\gamma \delta$ T-cell human glial cell interactions. I. In vitro induction of $\gamma \delta$ T-cell expansion by human glial cells. J Neuroimmunol. 1997; 74:135-142. [PubMed: 9119966]

223. Amor S, Smith PA, Hart BT, Baker D. Biozzi mice: of mice and human neurological diseases. J Neuroimmunol. 2005; 165:1-10. [PubMed: 16106527] 


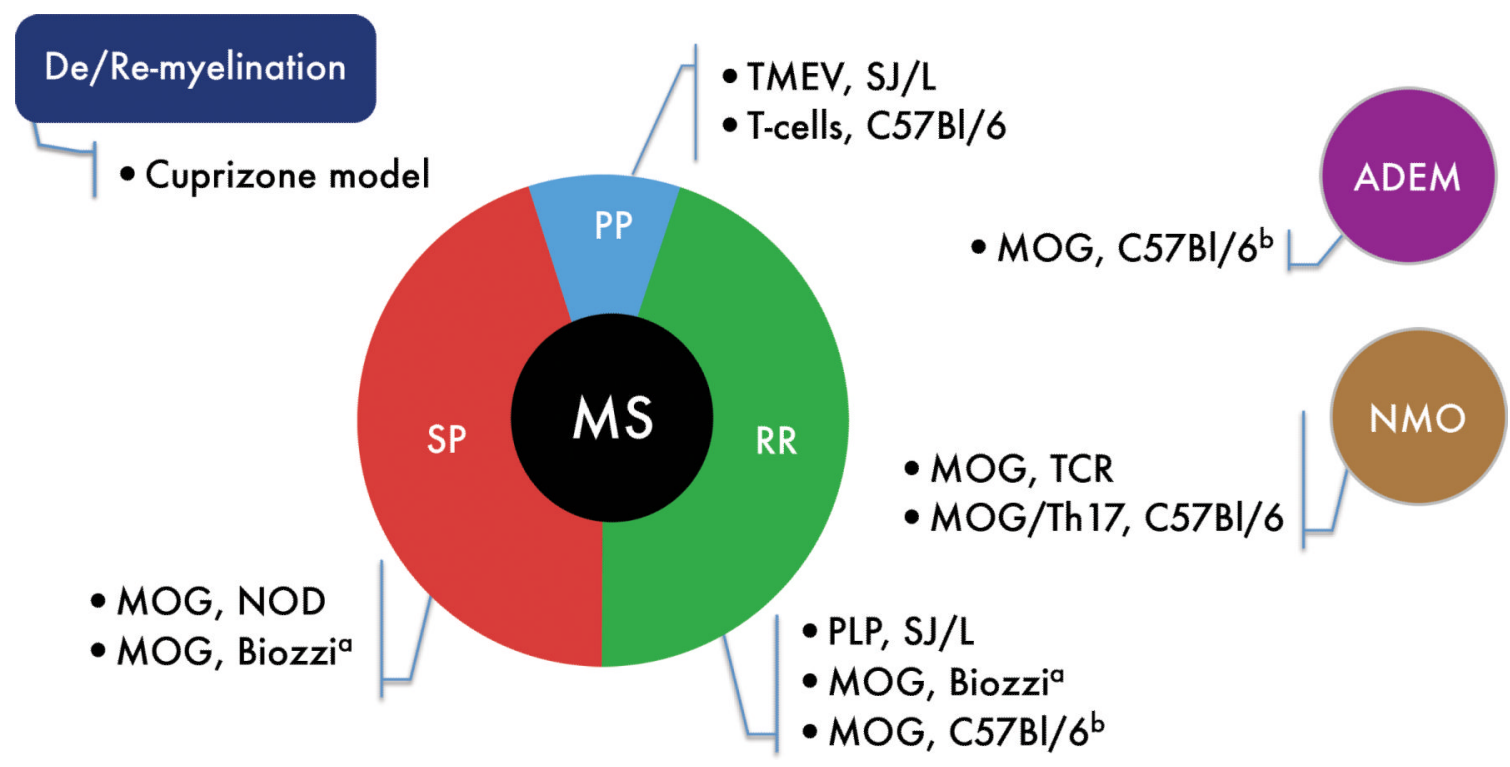

Fig. 1. Mouse models of demyelinating diseases

The demyelinating diseases multiple sclerosis (MS), neuromyelitis optica (NMO), and acute disseminated encephalomyelitis (ADEM), are represented as circles, with the corresponding mouse models. MS is further subdivided into a histogram representing the different stages of MS, a decade after initial diagnosis: primary progressive (PP), relapsing remitting (RR), and secondary progressive (SP). Data adapted from $(5,10,223)$. ${ }^{\text {B Biozzi mice develop a }}$ different EAE pattern depending on the peptide used for disease induction. ${ }^{\mathrm{b}} \mathrm{C} 57 \mathrm{B1} / 6 \mathrm{MOG}$ induced EAE is a monophasic disease that can be regarded as a single attack (ADEM) or represent the first attack in RRMS. 


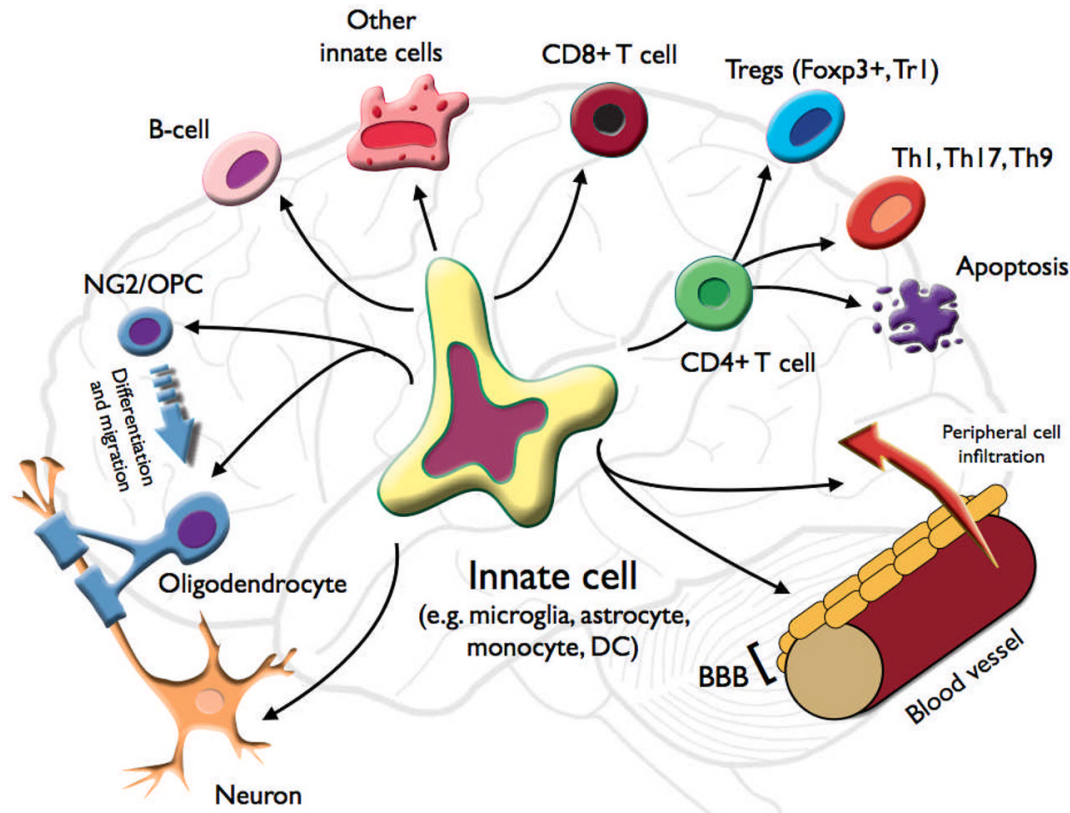

Fig. 2. Role of innate cells in modulating CNS demyelinating disease

An innate cell in the CNS may recruit peripheral cells and affect the integrity of the BBB. It can activate $\mathrm{CD}^{+}{ }^{+} \mathrm{T}$ cells and induce a pro-demyelinating effector phenotype (Th1, Th17, or Th9) or a regulatory T-cell phenotype (Foxp3 ${ }^{+}$Treg, and Tr1); or terminate the CD4 ${ }^{+}$ response by inducing apoptosis. The innate cell can also activate and modulate other adaptive cells such as $\mathrm{CD} 8^{+}$cytotoxic $\mathrm{T}$ cells, B cells, or other innate cells (either peripheral or central). The innate cell can directly affect the demyelinating and remyelinating processes by breaking down myelin, clearing (phagocytosis) myelin, debris, and dead cells, and by affecting oligodendrocyte and neuronal viability. The innate cell can also affect NG2/OPC (oligodendrocyte precursor cell) maturation into oligodendrocytes, and their migration to the lesion site, as well as modulating axonal growth. 


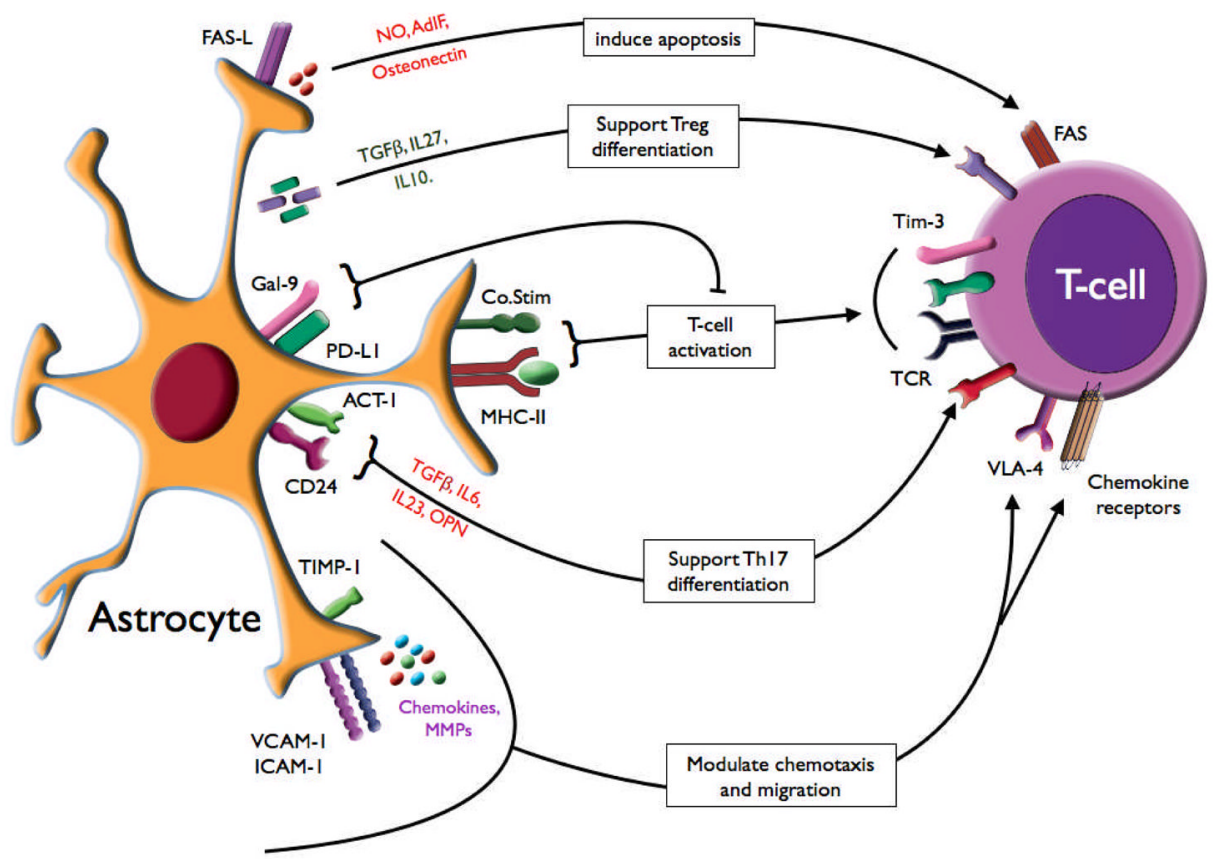

Fig. 3. Astrocyte modulation of $T$ cells

Astrocytes recruit $\mathrm{T}$ cells into the CNS by chemokine production, by expression of adhesion molecules (e.g. ICAM-1, VCAM-1), and by regulating passage through the BBB [by cytokine and MMP production or MMP inhibition (TIMP-1)]. Astrocytes induce T-cell activation via antigen presentation, cytokine production [TGF, IL-6, IL-23, IL-10, and osteopontin (OPN)], and use other signaling molecules to modulate the T-cell response [e.g. CD24, galectin-9 (Gal-9) and PD-L1]. Astrocytes may also prevent or terminate the T-cell response by inducing T-cell apoptosis, expression of FAS-L, or by other mediators such as nitric oxide, astrocyte-derived immune suppressor factor (AdIF), and osteonectin. 
Table 1

The role of astrocytes in demyelinating diseases.

\begin{tabular}{|c|c|}
\hline Function & Mechanism \\
\hline $\begin{array}{l}\text { Recruitment of immune cells to CNS lesion } \\
\text { sites }\end{array}$ & $\begin{array}{ll}\text { - } & \text { Chemokine production } \\
\text { - } & \text { Modulation of adhesion molecule expression (eg. VCAM-1) } \\
\text { - } & \text { Modulation of BBB integrity }\end{array}$ \\
\hline Modulation of the immune response & $\begin{array}{l}\text { Cytokines, chemokines, MHC, co-stimulatory molecules, secreted proteins (eg. MMPs), NO, } \\
\text { and ligand receptor interactions (eg. Gal9-Tim3) }\end{array}$ \\
\hline Termination of the immune response & Induction of apoptosis \\
\hline $\begin{array}{l}\text { Affect neuronal and oligodendrocyte } \\
\text { function }\end{array}$ & $\begin{array}{ll}\text { - } & \text { Viability (cytotoxicity or survival) } \\
\text { - } & \text { Regulation of axonal growth } \\
\text { - } & \text { Myelin breakdown and uptake (phagocytosis) }\end{array}$ \\
\hline $\begin{array}{l}\text { Modulation of the NG2/OPC role in } \\
\text { remyelination }\end{array}$ & $\begin{array}{ll}\text { - } & \text { Attraction of NG2/OPC to lesion sites } \\
\text { - } & \text { Regulation of NG2/OPC migration (eg. glia scar) } \\
\text { - } & \begin{array}{l}\text { Modulation of NG2/OPC survival, proliferation and differentiation into } \\
\text { oligodendrocytes }\end{array}\end{array}$ \\
\hline
\end{tabular}

